\title{
Prediction of Compression-After-Edge-Impact (CAEI) behaviour in composite panel stiffened with I-shaped stiffeners
}

\author{
N. Li ${ }^{\text {a }}$, P.H. Chen ${ }^{\text {a,* }}$ \\ a State Key Laboratory of Mechanics and Control of Mechanical Structures, Nanjing \\ University of Aeronautics and Astronautics ,Nanjing 210016, China \\ ${ }^{*}$ Corresponding author.
}

Tel: +8613813988209

E-mail address: phchen@nuaa.edu.cn

\begin{abstract}
A phenomenological-based mechanical finite element model is developed for the prediction of ultimate compression loads and failure modes of wing relevant composite panels stiffened with I-shaped stiffeners, of which the edge is subjected to impact loading. The initiation of intralaminar failure including fiber and inter-fiber fracture is evaluated by Puck criteria, and its evolution is assumed to be controlled by equivalent strains. The interlaminar failure, namely delamination, is simulated by employing a surface-based cohesive contact model. For R-sections of the impacted stiffener, interfacial delamination, which may cause premature failure and to some extent reduce the load carrying capacity, is efficiently considered. A good correlation between the experimental and numerical results shows correctness and effectiveness of the proposed mechanical method for predicting CAEI response. Furthermore, numerical results reveal that not only failure propagation of the impacted site but that of the other undamaged side dominate the compressive mechanism of the edge impacted stiffener, of which
\end{abstract}


complete fracture determines the ultimate failure load of the I-stiffened composite panel.

Keywords: B. Damage tolerance; B. Impact behaviour; C. Damage mechanics; C. Finite element analysis (FEA)

\section{Introduction}

Fiber reinforced composite materials are increasingly adopted as structural materials particularly in the aeronautic and astronautic applications when weight saving is a critical consideration. Unfortunately, during manufacturing operation and while in service, those materials are susceptible to damage from accidental low-velocity impact events. Extensive internal damage that may frequently remain invisible on the impacted surface can cause drastic reductions of the residual compressive strength when subjected to impact loading [1, 2]. Consequently, in the design of composite aeronautical structures, the impact damage tolerance of primary composite structures has inevitably been a major concern to improve the usable design strain level.

Depending upon the impact damage detectability, composite structures should be demonstrated the ability to tolerate accidental impacts of any possible critical locations at ultimate levels of load without failing. Stiffened composite panels, which are often applied to obtain lightweight structures with high bending stiffness and buckling resistance, are constructed with sheet material stabilized by many stiffeners whose free edges, however, remain vulnerable to foreign impacts. Due to the fact that the free edge lacks surrounding structures and is less constrained, more severe damage than classic skin impacts may be introduced, and in addition, residual properties of stiffened 
composite panels will be drastically reduced because a substantial portion of the panel load is carried by the stiffener [3, 4]. Therefore, the risk of severely reducing the load carrying capacity makes it necessary to investigate in detail the edge impact phenomenon and particularly corresponding Compression-After-Edge-Impact (CAEI) failure mechanisms, in order to identify the design parameters affecting the residual strength and improve the impact damage tolerance of stiffened composite panels.

A number of studies about the classic composite skin impact damage and relevant Compression-After-Impact (CAI) failure mechanisms are available in the literature, both theoretically and experimentally [5-9]. The compression residual strength relies heavily on the low-velocity impact damage characterization, such as conventional matrix cracking and delamination, existing in the laminate. Two distinct compressive failure phases can be observed in the previous experimental investigations of authors $[10,11]$ : the formation of the damage distributing region near the impact location and the catastrophic failure of the laminate. Impact-induced delamination is considered as a critical factor to the loss of stability of the sublaminate and subsequent stress redistribution that lowers residual strength. It indicates that local sublaminate buckling and subsequent delamination propagation are primarily responsible for the formation of damage region near the impact location. As the compression load increased, the dent contour on the impacted surface will evolve gradually from an approximately circular zone to an elliptic zone, where a strain concentration is observed in the boundary. As soon as the strain concentration reaches the compression failure strain, a clear crack, which is mainly caused by the compression fiber failure, propagates rapidly 
perpendicular to the loading direction, resulting in the catastrophic failure of the laminate [12]. Concerning the prediction of CAI strength, many analytical $[1,11,13]$ and numerical $[8,9,14,15]$ methods have been proposed. Continuum damage mechanics (CDM), as a predictive composite method, has been successfully employed to describe the complex intralaminar failure mechanisms in composite laminates in most of numerical methods. Besides, for the modeling issues of impact-induced delamination at multiple ply interfaces, the cohesive zone model (CZM) is explicitly used and proved its effectiveness.

Compared to the research effort associated with CAI issues of composite structures that are subjected to normal, transverse impact away from an edge, fewer studies have been published on the damage tolerance about free edge impact, and particularly, on the further analysis of the CAEI failure mechanism and assessment of residual strength. To the author's knowledge, only Rhead et al. [16] presents a semi-analytical fracture mechanics model, which assumes that final failure of composite laminates is caused by delamination buckling, in order to quickly predict the CAEI strength of T-stiffened composite panels. Malhotra [17] studies experimentally the effect of impact position for low velocity impact response and its correlation with CAEI strength for composite laminates. More recently, an inspiring experimental investigation, conducted by Ostre and Bouvet [18], replaces the whole T-stiffened panel with flat panels and elaborates the CAEI failure scenario. It shows that the propagation of compressive fiber failure determines the mechanisms that drive the laminate residual strength after edge impact. This present work is an extension of the experimental investigations [19] into the 
damage tolerance of wing relevant stiffened composite panels. From the numerical point of view, a phenomenological-based mechanical method has been proposed to estimate the residual strength and elaborate the post-impact compressive failure mechanism of the I-stiffened composite panel subjected to free edge impact. A detailed finite element model of the coupon has been established by incorporating edge impact-induced damage and using a global/local FE modeling technique. Finite element analyses have been conducted and the results, including global failure loads, final failure modes and strain distribution, are compared to the CAEI experiments to validate the FE model presented in this paper.

\section{Low velocity impact and CAEI tests}

\subsection{Materials and configurations of stiffened composite panels}

Dedicated experiments is designed and carried out to investigate the effect of free edge impact on the compression residual strength of stiffened composite panels that are constructed with sheet material stabilized by three I-shaped stiffeners. The low velocity impact is applied at the outside edge of the upper flange belonging to the central stiffener, as illustrated in Fig. 1(a). In order to ensure the uniform loading and prevent the premature failure at loading ends, both upper and lower ends of the stiffened panel are reinforced by epoxy resin blocks with steel frames in four sides and also the top of each block. The nominal width $(W)$ and nominal length $(L)$ of all test panels are about $505 \mathrm{~mm}$ and $790 \mathrm{~mm}$, respectively, while the reinforced blocks, with the height of 115 mm, reduce the effective length to $560 \mathrm{~mm}$, as shown in Fig. 1(b). The stiffeners are symmetric with respect to the longitudinal symmetry axis, and equally space with an 
interval $(D)$ of about $145 \mathrm{~mm}$ across width.

Three test configurations, referred to as Panel A-I, Panel B-I and Panel C-I according to different thickness and stacking sequences of their main items, are designed. Four specimens for each configuration are manufactured for the impact test and following CAEI test. I-shaped stiffeners are secondary bonded to the skin using Hysol@PL-7000 adhesive, and assembled from four separate laminates (see in Fig. 1(c)). Two curved laminates with the corner radius (r) of about $5 \mathrm{~mm}$ are placed back-to-back to form a I shape whose filler regions (R-sections) are filled with resin, whilst another two laminate are placed on the top and bottom to form the stiffener upper and bottom flanges, respectively. All specimens are designed with identical stiffener web height $(\mathrm{h}=$ $50 \mathrm{~mm})$ and same upper and bottom flange width $\left(\mathrm{b}_{1}=60 \mathrm{~mm}\right.$ and $\left.\mathrm{b}_{2}=40 \mathrm{~mm}\right)$. For Panels A-I, B-I and C-I, the nominal thickness of the web, upper and bottom flanges $\left(\mathrm{t}_{1}\right.$, $t_{2}$ and $t_{3}$ ) is identical, of which the value is $4.07 \mathrm{~mm}, 4.07 \mathrm{~mm}$ and $5.92 \mathrm{~mm}$ respectively, corresponding to the skin thickness (t) of $4.81 \mathrm{~mm}, 5.92 \mathrm{~mm}$ and $7.77 \mathrm{~mm}$.

The material of the skin and stiffener is graphite fiber reinforced epoxy composite CYCOM IMS/X850, of which the basic mechanical properties are presented in Table 2. The elastic modulus and Poisson's ratio of the resin in R-sections are $8.58 \mathrm{GPa}$ and 0.3 respectively. The stacking sequences of all the three test configurations are defined as following. The thickness of each layer is $0.185 \mathrm{~mm}$.

Panel A-I: [45/90/-45/0/-45/0/45/0/45/ $\left.0_{2} /-45 / 90\right]_{s}$ for the skin, and [45/90/-45/ $\left.0_{2} /-45 / 0_{3} / 45 / 0\right]_{\mathrm{s}}$ for the stiffener upper flange, bottom flange and stiffener web. 
Panel B-I: $\left[45 / 90 /-45 / 0_{2} /-45 / 0_{2} / 45 / 0_{2} / 45 / 0_{2} /-45 / 90\right]_{s}$ for the skin, and $\left[45 / 90 /-45 / 0_{2} /-45 / 0_{3} / 45 / 0\right]_{\mathrm{s}}$ for the stiffener upper flange, bottom flange and stiffener web.

Panel C-I: $\left[45 / 90 /-45 / 0_{3} /-45 / 0_{3} / 45 / 0_{3} / 45 / 0_{3} /-45 / 0 / 90\right]_{\mathrm{s}}$ for the skin, and [45/90/-45/ $\left.0_{2} /-45 / 0_{2} / 45 / 0_{2} / 45 / 0_{2} /-45 / 90\right]_{\mathrm{s}}$ for the stiffener upper flange, bottom flange and stiffener web.

\subsection{Test set up}

The edge impact damage is introduced before the compression test with the help of a vertical drop-weight impact instrument (Fig. 2(a)), which can set the required impact energy by adjusting the mass or the height of the impactor and also obtain the actual impact energy precisely with the velocity of the impactor measured by the velocity measuring device. Recently, there seems no existing method of determining the edge impact energy levels. Inspired from a reference to ASTM-D-7136M-05 standard which suggests that the impact energy of per unit thickness is $6.7 \mathrm{~J} / \mathrm{mm}$, the energy level of 32.2J that is equal to the skin impact energy level is applied for Panel A-I, while for Panels B-I and C-I, the specific values of edge impact energy levels are identified as 27.3J and 39.7J, respectively, according the thickness of each I-shaped stiffener upper flange.

Uniaxial compression tests are conducted on a hydraulic axial test machine called YES-W5000F with a maximum $5000 \mathrm{kN}$ load sensor accurate at $1.0 \%$ on the test range. During the test, the upper platform is locked by spherical hinge connection at the center, while the lower platform can be moved in a controlled speed with hydraulic actuator. 
Meanwhile, longitudinal edge supports with blade shape, as shown in Fig. 2(b), are applied at two lateral sides of the skin to avoid unintended buckling.

During the CAEI test phase, the strain levels of specimens are monitored by means of back-to-back strain gauges at each load increment until the complete failure. The data acquisition of the test strains is performed using a strain measure system DH3816. 84 uniaxial strain gauges and 36 rosette strain gauges in total are located on the I-stiffened panel, as shown in Fig. 3. Among them, 24 uniaxial strain gauges (G1 - G24) are bonded back-to-back on both sides of the skin for the purpose of distinguishing between the membrane strains and the bending stains. 60 strain gauges (G25 - G84), including 36 rosette strain gauges, are bonded on the bottom flanges of three stiffeners and the corresponding back side of the skin, in order to identify the potential debonding failure of the skin-to-stiffener interface. Besides, 36 strain gauges (G85 - G120) are located back-to-back on one side of the upper flanges and stiffener webs, which are able to provide information on the local buckling and subsequent damage propagation of the edge impacted stiffener.

\subsection{Edge impact experiment conclusions}

Irrespective of impact energy levels and stacking sequences, edge impact damage morphology of impact locations, as presented in Fig. 4, is basically consistent. The ultrasonic C-scan image of the edge impacted stiffener section (see Fig. 4(a)) shows that the projection of full delamination area approximately yields to a semi-elliptical shape, which is unlike an elliptical projected shape of delamination caused by normal skin impacts. The major axis of that delamination area directs along with the longitudinal 
orientation of the I-shaped stiffener, while the minor axis is along with the stiffener width. For I-stiffened panels A-I, B-I and C-I, the delamination size recorded has approximately the average major axis of $120 \mathrm{~mm}, 112 \mathrm{~mm}$ and $105 \mathrm{~mm}$, and the average minor axis of $20 \mathrm{~mm}$, $20 \mathrm{~mm}$ and $20 \mathrm{~mm}$.

Although only a permanent indentation can be barely detected by careful visual inspection on the impacted surface, as shown in Fig. 4(b), it can be seen from Fig. 4(c) that edge impact damage of an I-shaped stiffener is a quite complex interaction between three damage modes: matrix cracking, fiber fracture and delamination. Severe fiber failure and matrix cracks are localized in the indented zone, which is probably due to plasticity in composite materials [20] and blocking by impact-induced debris [21]. Rationally, this local indentation deformation induced by impact might has a major role on the propagation of internal cracks under compressive loading, due to the stress concentration caused by compression or a combination of compression and bending around the indented zone. Average values of the permanent indentation, measured more than $48 \mathrm{~h}$ after the impact test, are $0.35 \mathrm{~mm}, 0.41 \mathrm{~mm}$ and $0.44 \mathrm{~mm}$ for test Panels A-I, B-I and C-I, respectively.

\section{Finite element modeling technique}

\subsection{Composite damage model}

Continuum damage mechanics (CDM), as a predictive composite method recently, has been successfully employed to describe the complex intralaminar failure mechanisms in composite laminates. In order to characterize internal damage, a constitutive relation between damaged and intact materials is established in the CDM 
method, by taking into account internal thermodynamically irreversible damage variables that act as a measure of local damage in a Representative Volume Element (RVE) of the composite material. Once damage initiation that is predicted with either stress or strain failure criteria, material properties are progressively degraded until enough energy is absorbed for complete failure as damage is accumulated, to represent the damage propagation.

\subsubsection{Damage initiation}

The Puck’s failure criteria, based on Mohr’s fracture hypothesis assuming the occurrence of a fracture plane induced by intrinsically brittle failure of composites, are implemented for predicting matrix-dominated damage behaviour. When considering that the thickness of laminated plates is far smaller than the dimensions in other two directions, a 2D stress and strength analysis is sufficient due to little effect of interlaminar stresses on the intralaminar failure. By this way, no numerical search of the potential fracture plane angle is required for inter-fiber tension fracture (IFF) failure, which of course can reduce computational cost significantly. According to the fracture plane’s normal stress, 2D Puck’s failure criteria divide IFF failure into three different modes, namely Mode A (transverse tension), Mode B (moderate transverse compression) and Mode C (large transverse compression) defined as follows:

Inter-fiber fracture in transverse tension (IFFT in Mode A):

$$
\sigma_{2} \geq 0 \rightarrow f_{\mathrm{IFF}}=\sqrt{\left[\left(\frac{1}{R_{\perp}^{\mathrm{t}}}-\frac{p_{\perp \|}^{\mathrm{t}}}{R_{\perp \|}}\right) \sigma_{2}\right]^{2}+\left(\frac{\tau_{21}}{R_{\perp \|}}\right)^{2}}+\frac{p_{\perp \|}^{\mathrm{t}}}{R_{\perp \|}} \sigma_{2}
$$

Inter-fiber fracture in moderate transverse compression (IFFC in Mode B): 
$\sigma_{2}<0 \wedge\left|\frac{\sigma_{2}}{\tau_{21}}\right| \leq\left|\frac{R_{\perp \perp}^{\mathrm{A}}}{\tau_{21, c}}\right| \rightarrow f_{\mathrm{IFF}}=\sqrt{\left(\frac{p_{\perp \|}^{\mathrm{c}}}{R_{\perp \|}} \sigma_{2}\right)^{2}+\left(\frac{\tau_{21}}{R_{\perp \|}}\right)^{2}}+\frac{p_{\perp \|}^{\mathrm{c}}}{R_{\perp \|}} \sigma_{2}$

Inter-fiber fracture in large transverse compression (IFFC in Mode C):

$\sigma_{2}<0 \wedge\left|\frac{\sigma_{2}}{\tau_{21}}\right|>\left|\frac{R_{\perp \perp}^{\mathrm{A}}}{\tau_{21, c}}\right| \rightarrow f_{\mathrm{IFF}}=\left[\left(\frac{\tau_{21}}{2\left(1+p_{\perp \perp}^{\mathrm{c}}\right) R_{\perp \|}}\right)^{2}+\left(\frac{\sigma_{2}}{R_{\perp}^{c}}\right)^{2}\right] \frac{R_{\perp}^{c}}{-\sigma_{2}}$

with $\frac{p_{\perp \perp}^{\mathrm{c}}}{R_{\perp \perp}^{\mathrm{A}}}=\frac{p_{\perp \|}^{\mathrm{c}}}{R_{\perp \|}}$ and $\tau_{21, c}=R_{\perp \|} \sqrt{1+2 p_{\perp \perp}^{\mathrm{c}}}$

where $R_{\perp}^{\mathrm{t}}$ and $R_{\perp}^{\mathrm{c}}$ are the tensile and compressive strength against the transverse

direction. $R_{\perp \|}$ denotes the longitudinal or transverse shear strength. $p_{\perp \|}^{\mathrm{t}}, \quad p_{\perp \perp}^{\mathrm{t}}, \quad p_{\perp \|}^{\mathrm{c}}$ and $p_{\perp \perp}^{\mathrm{c}}$ are the inclination parameters of contour lines of the master fracture body.

Typically, specific values of these inclination parameters are recommended [22, 35] in the absence of relevant experimental data, as listed in Table 1. With the help of above recommended values of inclination parameters, Puck's criteria could achieve good agreement between the predictions and experiments with different loading conditions and specimen configurations [36-38]. Therefore the present analysis followed the recommendation given in for the specific values of $0.35,0.30,0.27$ and 0.27 , respectively.

When the global maximum value of the function $f_{\text {IFF }}$ reaches 1.0, IFF failure is considered to occur. The fracture occurs on the plane perpendicular to the transverse direction $\left(\theta_{\mathrm{fp}}=0^{\circ}\right)$ corresponding to the fracture modes of both Mode A and Mode B, while the fracture angle $\theta_{\mathrm{fp}}$ of Mode $\mathrm{C}$ can be calculated by

$$
\cos \theta_{\mathrm{fp}}=\sqrt{\frac{1}{2\left(1+p_{\perp \perp}^{\mathrm{c}}\right)}\left[\left(\frac{R_{\perp \perp}^{\mathrm{A}} \tau_{21}}{R_{\perp \|} \sigma_{2}}\right)^{2}+1\right]}
$$


Fiber fracture (FF) is primarily caused by the stress (strain) acting parallel to the longitudinal direction. The FF criteria, taking into account the influence of a transverse Poisson's effect, is defined as

Fiber tension fracture (FFT):

$$
\varepsilon_{1} \geq 0 \rightarrow f_{\mathrm{FF}}=\frac{1}{\varepsilon_{1, \mathrm{~T}}}\left(\varepsilon_{1}+\frac{v_{\mathrm{f} 12}}{E_{\mathrm{f} 1}} m_{\sigma \mathrm{f}} \sigma_{2}\right)
$$

Fiber compression fracture (FFC):

$$
\varepsilon_{1}<0 \rightarrow f_{\mathrm{FF}}=\frac{1}{\varepsilon_{1, \mathrm{C}}}\left|\left(\varepsilon_{1}+\frac{v_{\mathrm{f} 12}}{E_{\mathrm{f} 1}} m_{\sigma \mathrm{f}} \sigma_{2}\right)\right|+\left(10 \gamma_{21}\right)^{2}
$$

where $\varepsilon_{1, \mathrm{~T}}$ and $\varepsilon_{1, \mathrm{C}}$ are the tensile and compressive failure strains of the UD laminate in the fiber direction, respectively. $E_{\mathrm{f} 1}$ and $v_{\mathrm{f} 12}$ are Young modulus and Poisson's ratio for the fibers, respectively. $m_{\sigma \mathrm{f}}$ is a magnification factor for the transverse stress in the fibers (for GFRP $m_{\sigma \mathrm{f}} \approx 1.3$ and for CFRP $m_{\sigma \mathrm{f}} \approx 1.1$ as recommendation in [22]). The FF occurs as soon as the value of $f_{\mathrm{FF}}$ reaches 1.0.

\subsubsection{Damage evolution}

Once damage initiation, a damage variable matrix $\boldsymbol{M}(\boldsymbol{D})$ is employed to characterize the severity of damage and effective fractional reduction of load carrying area. The effective stress of the material with micro cracks, based on the damage tensor, can be defined as follows

$$
\bar{\sigma}=M(D) \cdot \sigma
$$

where in the plane stress condition, $\boldsymbol{M}(\boldsymbol{D})=\operatorname{diag}\left[1 / \omega_{11}, 1 / \omega_{22}, 1 / \omega_{12}\right], \omega_{11}=1-d_{1}$, $\omega_{22}=1-d_{2}$ and $\omega_{12}=\left(1-d_{1}\right)\left(1-d_{2}\right)$.

Based on the strain energy for the intact material, the equivalence strain energy for the damaged material is following 
$W_{\mathrm{d}}=\frac{1}{2} \overline{\boldsymbol{\sigma}} \cdot \boldsymbol{C}_{0}^{-1} \cdot \overline{\boldsymbol{\sigma}}=\frac{1}{2} \boldsymbol{\sigma} \cdot \boldsymbol{M}(\boldsymbol{D})^{\mathrm{T}} \cdot \boldsymbol{C}_{0}^{-1} \cdot \boldsymbol{M}(\boldsymbol{D}) \cdot \boldsymbol{\sigma}=\frac{1}{2} \boldsymbol{\sigma} \cdot \boldsymbol{C}_{\mathrm{d}}^{-1} \cdot \boldsymbol{\sigma}$

where $\boldsymbol{C}_{\mathrm{d}}=\boldsymbol{M}(\boldsymbol{D})^{-1} \cdot \boldsymbol{C}_{0}^{-1} \cdot \boldsymbol{M}(\boldsymbol{D})^{-\mathrm{T}}$ is the damage constitutive of composite materials.

A strong mesh dependency of finite element results in that the energy dissipated

decreases upon mesh refinement will be caused by strain localization. Due to the fact

that the energy dissipated in the damage propagation phase is proportional to the

element size, a crack band model [39] is used to reduce the sensitivity to the mesh size.

During the post-damage initiation phase, a linear strain-softening evolution law

with a negative slope is proposed according to the fracture energy dissipated, so as to

represent damage propagation associated with a reduction in material secant stiffness.

The equivalent strain at final failure, $\varepsilon_{\text {eq }}^{\mathrm{f}}$, can be derived from

$\varepsilon_{\text {eq }}^{\mathrm{f}}=\frac{2 G_{\mathrm{c}}}{\sigma_{\text {eq }}^{0} L^{\mathrm{c}}}=\frac{2 g_{\mathrm{c}}}{\sigma_{\text {eq }}^{0}}$

where $\sigma_{\mathrm{eq}}^{0}$ is the equivalent stress at damage initiation. $G_{\mathrm{c}}$ is the critical fracture

energy. $g_{\mathrm{c}}$ is the critical fracture energy density smeared in the characteristic length.

$L^{\mathrm{c}}$ is the characteristic length that will keep a constant energy release rate per unit area

of the crack. For a plane element, according to the work published by Lapczyk [40], the specific value of the characteristic length at each integration point can be assumed to be equal to the square root of the element area. This computing process is implemented by a user-defined material subroutine (VUMAT) in this paper.

Following a bi-linear constitutive relationship, the internal damage variable, $d^{\mathrm{I}}$, corresponding to four damage modes at each time step is given by

$d^{\mathrm{I}}=\max \left\{0, \min \left\{1, \varepsilon_{\mathrm{eq}, \mathrm{I}}^{\mathrm{f}} \frac{\varepsilon_{\mathrm{eq}, \mathrm{I}}-\varepsilon_{\mathrm{eq}, \mathrm{I}}^{0}}{\varepsilon_{\mathrm{eq}, \mathrm{I}}\left(\varepsilon_{\mathrm{eq}, \mathrm{I}}^{\mathrm{f}}-\varepsilon_{\mathrm{eq}, \mathrm{I}}^{0}\right)}\right\}\right\} \quad \mathrm{I} \in(\mathrm{FFT}, \mathrm{FFC}, \mathrm{IFFT}, \mathrm{IFFC})$ 
where $\varepsilon_{\text {eq,I }}, \varepsilon_{\text {eq,I }}^{0}$ and $\varepsilon_{\text {eq,I }}^{\mathrm{f}}$ are the equivalent strains at the current phase, damage initiation and final failure, respectively. Damage irreversibility can be accounted for with the functional form 'max'.

Considering the effect of IFF on material behavior depends on whether or not crack faces are in contact, the damage variables associated with intralaminar failure is defined as

$$
\begin{aligned}
& d_{1}=1-\left(1-d^{\mathrm{FFT}}\right)\left(1-d^{\mathrm{FFC}}\right), d_{2}=\max \left(\frac{\left\langle\sigma_{2}\right\rangle}{\left|\sigma_{2}\right|} d^{\mathrm{IFFC}}, d^{\mathrm{IFFT}}\right) \text { and } \\
& d_{12}=1-\left(1-d^{\mathrm{FFT}}\right)\left(1-d^{\mathrm{FFC}}\right)\left(1-d^{\mathrm{IFFT}}\right)\left(1-d^{\mathrm{IFFC}}\right)
\end{aligned}
$$

where $\langle\bullet\rangle$ is the McCauley operator, defined as $\langle x\rangle=(x+|x|) / 2$ for $x \in \mathfrak{R}$.

The interaction of stress $\sigma_{2}$ and $\tau_{21}$ is the dominant factor driving the brittle fracture of matrix, because IFF failure is attributed to loading in transverse and shear directions according to Puck's IFF criteria. Similarly, the stress in the longitudinal direction $\sigma_{1}$ drives the FF failure. Therefore, for IFF and FF failure respectively, the equivalent stress and corresponding strain are

$$
\begin{aligned}
& \sigma_{\text {eq,IFF }}=\sqrt{\left\langle\sigma_{2}\right\rangle^{2}+\tau_{21}^{2}}, \quad \varepsilon_{\text {eq,IFF }}=\sqrt{\left\langle\varepsilon_{2}\right\rangle^{2}+\gamma_{21}^{2}} \\
& \sigma_{\text {eq,FF }}=\sqrt{\sigma_{1}^{2}}, \quad \varepsilon_{\text {eq }, \mathrm{FF}}=\sqrt{\varepsilon_{1}^{2}}
\end{aligned}
$$

Onset failure stress and strain ( $\sigma_{\text {eq }}^{0}$ and $\varepsilon_{\text {eq }}^{0}$ in Eq. (14)) respectively correspond to the equivalent stress and strain when the value of damage function $f_{\mathrm{IFF}}$ or $f_{\mathrm{FF}}$ is equal to 1.0. The strain at final failure, $\varepsilon_{\text {eq }}^{\mathrm{f}}$, is obtained by the damage evolution law, which prescribes equality between the dissipation of the strain energy density and the critical fracture energy density as complete destruction. Based on the strain energy release density in material, a quadratic interaction function for the fracture energy in the 
mix-mode case can be established.

$\left(\frac{g_{2}^{\mathrm{k}} L^{\mathrm{c}}}{G_{2 \mathrm{c}}^{\mathrm{k}}}\right)^{2}+\left(\frac{g_{21}}{G_{21 \mathrm{c}}}\right)^{2}=1$

where $g_{2}^{\mathrm{k}}$ and $g_{21}$ are the strain energy release densities related to stresses $\sigma_{2}$ and $\tau_{21}$, respectively. $G_{2 \mathrm{c}}^{\mathrm{k}}$ and $G_{21 \mathrm{c}}$ are the critical fracture energy release rates

respectively corresponding to transverse tension or compression and in-plane shear.

Among them, the superscript $\mathrm{k}(\mathrm{k}=\mathrm{t}, \mathrm{c})$ denotes the tensile or compressive load.

The strain energy density released in the characteristic length, due to complete IFF failure, $g_{i}^{\mathrm{f}}$ can be given in

$g_{i}^{\mathrm{f}}=\int_{0}^{\varepsilon_{i}^{\mathrm{f}}} \sigma_{i} \mathrm{~d} \varepsilon \approx \frac{1}{2} \sigma_{i}^{0} \varepsilon_{i}^{\mathrm{f}}=\frac{1}{2} \sigma_{i}^{0} \beta_{i} \varepsilon_{\mathrm{eq}}^{\mathrm{f}} \quad(i=2,21)$

where $\sigma_{i}^{0}$ is the stress component at IFF failure initiation. $\beta_{i}$ denotes the mix-mode ratio and can be expressed as

$\beta_{n}=\frac{\left\langle\varepsilon_{2}\right\rangle}{\varepsilon_{\text {eq }}}, \quad \beta_{21}=\frac{\gamma_{21}}{\varepsilon_{\text {eq }}}$

The equivalent strain at final IFF failure is obtained by substituting the result of Eq.

(14) into Eq. (13).

$\varepsilon_{\text {eq,IFF }}^{\mathrm{f}}=\frac{2}{L^{\mathrm{c}}}\left[\left(\frac{\sigma_{2}^{0} \beta_{2}}{G_{2 \mathrm{c}}^{\mathrm{k}}}\right)^{2}+\left(\frac{\tau_{21}^{0} \beta_{21}}{G_{21 \mathrm{c}}}\right)^{2}\right]^{-1 / 2}$

The final failure strain, at which FF failure across the element occurs, is

determined by

$\varepsilon_{\mathrm{eq}, \mathrm{FF}}^{\mathrm{f}}=\frac{2 g_{1 \mathrm{c}}^{\mathrm{k}}}{R_{\|}^{\mathrm{k}}}=\frac{2 G_{1 \mathrm{c}}^{\mathrm{k}}}{R_{\|}^{\mathrm{k}} L^{\mathrm{c}}}$

where the superscript $\mathrm{k}(\mathrm{k}=\mathrm{t}, \mathrm{c})$ denotes the tensile or compressive load, $G_{1 \mathrm{c}}^{\mathrm{k}}$ is the critical fracture energy release rate of FF failure. 


\subsubsection{Delamination}

Generally, cohesive zone model (CZM), which is based on the relative displacements and stresses between interfaces, has been employed to simulate the initiation and propagation of the delamination failure in composite laminates. In the present study, a surface-based cohesive behaviour [23] is used to capture delamination by the application of generalised traction-separation behaviour for two adjacent surfaces. In contrast to cohesive interface elements, this in-built approach of the FE package ABAQUS is typically convenient to simulate the cohesive connections without defining specific cohesive elements and tie constraints, and also allows simulation of other cohesive interactions, such as contact phenomena of adjacent surfaces, except for the interlaminar damage.

The mix-mode failure is assumed to initiate when a quadratic interaction function involving the interface stress ratios reaches a value of one. This quadratic stress criterion can be represented as

$$
\left(\frac{\left\langle t_{n}\right\rangle}{t_{n}^{0}}\right)^{2}+\left(\frac{t_{s}}{t_{s}^{0}}\right)^{2}+\left(\frac{t_{t}}{t_{t}^{0}}\right)^{2}=1
$$

where $t_{i}(i=n, s, t)$ denote interfacial stresses in the normal, the first and the second shear directions respectively, and $t_{i}^{0}$ are the corresponding strength associated with each direction.

The interfacial strength, which is used to evaluate the onset of delamination, might not be obtained by tests directly. Because in the short beam shear test, the interlaminar shear strength is evaluated by the ultimate failure load rather than the shear stress characterizing the onset of delamination. A micromechanical model based on equivalent 
inclusion method (EIM) has been applied for predicting the initial interlaminar shear strength [24]. The cohesive strength based on the assumption that delamination initiates due to matrix cracking, can be taken as the value of the interface stress when the maximum of the matrix stress in the cohesive layer initially reaches to the matrix strength. A zoom factor is proposed to represent the linear relationship between the interface stress and the matrix stress before the matrix crack initiates. For the composite material IMS/X850, the values of zoom factors $A_{\mathrm{N}}, A_{\mathrm{S}}, A_{\mathrm{T}}$, which can be determined by a micromechanical model based on EIM, are about $0.579,0.704$ and 0.704 , respectively [25]. Thus, the corresponding strength of cohesive elements is: $t_{n}^{0}=51 \mathrm{MPa}$, $t_{s}^{0}=t_{n}^{0}=62 \mathrm{MPa}$

However, the results predicted by the cohesive model with coarse meshes are strongly sensitive to mesh sizes. In order to obtain accurate results, extremely refined meshes within the cohesive zone are required and therefore will directly result in long calculation time. To avoid using very fine meshes, an engineering solution, proposed by Turon et al. [26], can still accurately capture the softening behaviour ahead of the crack tip through reducing interface strength with a coarser mesh size. This interface strength with a coarser mesh size is estimated as $\bar{t}_{i}^{0}=t_{i}^{0} \sqrt{\frac{l_{e}^{0}}{\bar{l}_{e}}} \quad(i=n, s, t)$

where $\bar{l}_{e}$ is the mesh size in the direction of crack propagation and $l_{e}^{0}$ is the critical mesh size that requires at least two elements to represent the distribution of tractions ahead of the crack tip for an accurate representation. The value of $l_{e}^{0}$ is usually set equal to $0.5 \mathrm{~mm}$, due to the fact that for a mesh size greater than $0.5 \mathrm{~mm}$, fewer than two 
elements will span the cohesive zone [41]. Hence, in the numerical simulation, the cohesive strength of $\bar{t}_{n}^{0}, \bar{t}_{s}^{0}$ and ${\overline{t_{t}}}^{0}$ are 22.8 $\mathrm{MPa}, 27.7 \mathrm{MPa}$ and 27.7 $\mathrm{MPa}$ respectively, yielding a fine mesh size of $2.5 \mathrm{~mm}$.

The propagation of delamination was governed by B-K propagation criterion,

$$
G_{\mathrm{c}}=G_{\text {Ic }}+\left(G_{\text {IIC }}-G_{\text {Ic }}\right)\left(\frac{G_{\text {II }}+G_{\text {III }}}{G_{\text {I }}+G_{\text {II }}+G_{\text {III }}}\right)^{\eta}
$$

where $G_{\text {c }}$ is the mix-mode fracture energy rate, $G_{\text {Ic }}$ and $G_{\text {IIc }}$ are the critical energy release rate for mode I and mode II fracture respectively, $G_{\mathrm{I}}, G_{\mathrm{II}}$ and $G_{\mathrm{III}}$ refer to the work done by the traction and its conjugate relative displacement in the normal, the first, and the second shear directions, respectively. And $\eta$ is the mixed-mode interaction determined from experimental measurements. The values of critical energy release rate for mode I fracture $\left(G_{\text {IC }}\right)$ and mode II fracture $\left(G_{\text {IIc }}\right)$ can be measured by means of the dual cantilever beam (DCB) test and edge notched flexure (ENF) test. Therefore, for the composite material IMS/X850 (see in Table 2), the values of $G_{\text {Ic }}$ and $G_{\text {IIc }}$ are $0.314 \mathrm{~N} \cdot \mathrm{mm}^{-1}$ and $1.081 \mathrm{~N} \cdot \mathrm{mm}^{-1}$, respectively.

\subsection{Simplified method for incorporating edge impact damage}

Accurate evaluation of residual strength is always a problem with great complexity for incorporating damage types induced by edge impacts. It is necessary to account accurately for the state and extent of impact damage and simulating this damage in the reasonable constitutive relationships, for the development of a model that can deal with various impact energies and stacking sequences. Over the years, a FE method for considering overall failure process, including both impact and CAI experiments, has been proposed [9, 10, 27]. However, this accurate method available seems to be 
computationally expensive as it requires detailed time-consuming progressive damage calculations based on the 3D stress state and makes use of cohesive elements which should be placed accurately at each interface between plies. Along with the increase of ply amounts, it is more impractical and inefficient to investigate the CAI performance through establishing a whole structural model with detailed geometries and distribution of impact damage.

Indeed as far as the authors are aware there seems to be a lack of available methods regarding the prediction of CAEI behaviour of I-stiffened composite panels. A physically-based method, taking both the shape, number of the delamination and the intralaminar damage (matrix cracking and fiber fracture), is proposed to simplify post-impact damage of the I-shaped stiffener edge.

The impacted flange is typically divided in three regions as shown in Fig. 5(a), based the experimental post-impact morphology of all specimens. The region with severe fiber and matrix damage, namely around the indented zone, defines the first semi-elliptical inclusion. The region between the boundary of the first inclusion and the maximum envelope of delamination is the second semi-elliptical inclusion. The main intralaminar failure mode in the second inclusion is assumed to be matrix damage, due to the fact that initiation of delamination is mostly caused by matrix cracking $[28,29]$. Though, of course, it should be emphasized that the delamination caused by stiffness mismatch and the relative motion between the debonding plies is neglected for simplification. Beyond the second elliptical inclusion, the upper flange is intact.

The first and second inclusion regions provide the softening influence of local 
stiffness reduction representing the fiber and matrix damage. But besides that, a great deal of fiber breakage and matrix cracks, which are caused by the impactor's pressure, form in the plies adjacent to the impact surface (Zone I), as shown in Fig. 5(b). The entire material in Zone I no longer sustains any load. Moreover, the tensile fracture cracks in the plies away from the impactor (Zone III) are more likely to act as free edges, causing a local kink in the buckling shape rather than as a softened region where the fibers broom and intersect under the compressive load [30]. Accordingly, for the first inclusion region with core damage, except for the Zones I and III that are treated as a semi-elliptic hole, the material properties for each ply in the Zone II are updated as follows: the longitudinal Young modulus $E_{11}$, transverse Young modulus $E_{22}$ and in-plane shear modulus $G_{12}$ are set to $5 \%$ of their pristine values. These stiffness reductions are done over the radial distance from the indented center to the boundary where core damage occurs. For the second inclusion region with matrix damage, transverse Young modulus $E_{22}$ and in-plane shear modulus $G_{12}$ are set to $20 \%$ of their pristine values, based on the stiffness degradation model proposed by Camanho [31]. On the basis of the assumed condition that the delamination areas with smaller sizes have little effect on the compression response [32], multiple delamination carcks can be approximated by some severe delamination failure at critical interfaces, in order to improve the computational efficiency. Thus at each application it is supposed that only the examined interfaces with larger delamination sizes is present in the simplified model and those all secondary effects, such as friction between delaminated plies, are neglected. The delamination scenario induced by edge impact is assumed to be 
approximately semi-elliptical in shape, as illustrated in Fig. 6(a).

After low-velocity impact, in general, the out-of-plane deformation near the impacted region will be formed permanently. In the subsequent CAEI experiment, rationally, this local indentation deformation will introduce additional out-of-plane bending moment, which will cause the stress concentration around the indented zone and then accelerate the occurrence of matrix cracking and fiber fracture. It suggests that the permanent indentation induced by impact might play an important role on the extreme fracture of the impacted flange, and this phenomenon should be taken into account in the proposed model to realistically replicate the experimental results.

Consequently, the simulation is performed in two steps. The first step corresponds to the introduction of the permanent indentation, with the stiffened panel clamped at two ends. A displacement, of which magnitude is set equal to the measured value of the dent depth, is applied at the edge impact location, as shown in Fig. 6(b). Afterwards in the second CAEI step, the structural deformation gained in the first step is treated as a geometric imperfection, and an imposed displacement is incremented up to the final failure of the stiffened composite panel.

\subsection{Global-local modelling strategy}

The Abaqus/Explicit code is used to run the numerical FE model where the composite damage model, together with the proposed simplified method for incorporating damage induced by free edge impacts, is implemented. The composite panels are discretized using the continuum shell elements (SC8R), each having eight nodes with three degrees of freedom at each node. The FE model simulates the 
geometry as described in Section 2.1. The input material properties used in the numerical simulation is partly presented in Table 2 . Besides, thanks to identical fracture modes, the critical fracture energy release rates corresponding to transverse tension and in-plane shear ( $G_{2 \mathrm{c}}^{\mathrm{t}}$ and $G_{21 \mathrm{c}}$ ) can be set equal to the values of mode I and mode II fracture energy release rates ( $G_{\text {Ic }}$ and $G_{\text {II }}$ ). The critical fracture energy release rate corresponding to transverse compression, $G_{2 c}^{\mathrm{c}}$, can be calculated approximately using the mode II component of the critical fracture energy release rates and the fracture angle $\left(G_{2 \mathrm{c}}^{\mathrm{c}} \approx G_{21 \mathrm{c}} / \cos \alpha_{0}=G_{21 \mathrm{c}} / \cos 53^{\circ}\right)$. The critical fracture energy release rates corresponding to FF failure are the following [9]: $G_{1 \mathrm{c}}^{\mathrm{t}}=133 \mathrm{~N} \cdot \mathrm{mm}^{-1}$, $G_{1 \mathrm{c}}^{\mathrm{c}}=10 \mathrm{~N} \cdot \mathrm{mm}^{-1}$.

Fig. 7(a) gives the numerical CAEI model of a stiffened composite panel. A global-local technique has been applied to reduce high computational costs. A refined mesh (2.5 mm element average size) has been adopted in the central part of the stiffened composite panel, including the edge impacted stiffener and corresponding skin (local region), while a coarser mesh (6 mm element average size) has been considered in the rest of model (global region). "Tie-constraints" contact algorithms have been used to link the node degrees of freedom at the global-local interface.

A simplified method, described in Section 3.2, is adopted to incorporate the initial damage induced by edge impact. Due to the identical configuration and stacking sequences of the impacted stiffener, the post-impact damage morphology of Panel B-I is similar to that of Panel A-I. The larger delamination under impact loading is observed between the 9th and 10th plies, and the 13rd and 14th plies for both Panels A-I and B-I, 
while that is between 14th and 15th plies, and the 18td and 19th plies for Panel C-I. The areas of delamination between the rest of plies are neglected in the numerical simulation, due to the fact that their sizes are small and do not significantly affect the CAEI response. In addition, the first inclusion region with core damage has approximately the average semimajor axis of $7 \mathrm{~mm}, 7 \mathrm{~mm}$ and $6.5 \mathrm{~mm}$, and the average semiminor axis of $5 \mathrm{~mm}, 5 \mathrm{~mm}$ and $5 \mathrm{~mm}$ for Panels A-I, B-I and C-I, respectively. Similarly, the thickness of Zone I that mainly contains compressive intralaminar damge is considered equal to $1.665 \mathrm{~mm}, 1.665 \mathrm{~mm}$ and $2.59 \mathrm{~mm}$, while that of Zone III, containing tensile cracks, is 0.555mm, $0.555 \mathrm{~mm}$ and $0.925 \mathrm{~mm}$ for Panels A-I, B-I and C-I, respectively. The relevant geometric parameters of second inclusion region with matrix damage are considered equal to the delamination sizes that are mentioned previously in Section 2.3.

It should be noted that high interlaminar stresses which may cause delamination can arise from the curved laminates, because of geometric discontinuities, material discontinuities and eccentricities in the load path. One example of a generic curved laminate, of which the compressive strength may be reduced significantly due to the premature delamination, is the R-sections of the stiffener (Fig. 7(b)). In particular, for the specific CAEI issue, additional bending moments, caused by the asymmetry of bearing loads around the edge impacted region, will be imposed on the R-sections and promote the fracture of impacted stiffener under compression. To take the delamination of R-sections into account and meanwhile reduce the number of interfaces where the cohesive elements need to be defined, an efficient approach [33] is conducted to determine the potential failure location under the critical force. Firstly, considering a 
laminate with multiple isotropic plies, a classical laminate plate theory [34] is employed to regard the laminate as a homogeneous anisotropic plate and calculate its equivalent elastic moduli. Then, according to using the plane strain hypothesis, the stress distribution due to bending moment $M_{0}$, axial force $N_{0}$ and shear force $S_{0}$ in Fig. 7(c) can be obtained as following.

$$
\begin{aligned}
& \sigma_{r}(r, \theta)=\frac{M_{0}+N_{0}(a+b) / 2}{g b^{2}}\left[1-\frac{1-c^{k+1}}{1-c^{2 k}} \cdot\left(\frac{r}{b}\right)^{k-1}-\frac{1-c^{k-1}}{1-c^{2 k}} \cdot\left(\frac{b c}{r}\right)^{k+1}\right] \\
& +\frac{\left(N_{0} \cos \theta+S_{0} \sin \theta\right)}{g_{1} r}\left[\left(\frac{r}{b}\right)^{\beta}+c^{\beta}\left(\frac{b}{r}\right)^{\beta}-1-c^{\beta}\right] \\
& \sigma_{\theta}(r, \theta)=\frac{\left(N_{0} \cos \theta+S_{0} \sin \theta\right)}{g_{1} r}\left[(1+\beta)\left(\frac{r}{b}\right)^{\beta}+c^{\beta}(1-\beta)\left(\frac{b}{r}\right)^{\beta}-1-c^{\beta}\right] \\
& +\frac{M_{0}+N_{0}(a+b) / 2}{g b^{2}}\left[1-\frac{1-c^{k+1}}{1-c^{2 k}} \cdot k\left(\frac{r}{b}\right)^{k-1}+\frac{1-c^{k-1}}{1-c^{2 k}} k\left(\frac{b c}{r}\right)^{k+1}\right] \\
& \tau_{r \theta}(r, \theta)=\frac{1}{g_{1} r}\left[\left(\frac{r}{b}\right)^{\beta}+c^{\beta}\left(\frac{b}{r}\right)^{\beta}-1-c^{\beta}\right]\left(S_{0} \cos \theta-N_{0} \sin \theta\right) \\
& \text { where, } \beta=\sqrt{1+\frac{\beta_{11}+2 \beta_{12}+\beta_{22}}{\beta_{66}}}, \quad \beta_{11}=\frac{1}{E_{r}}-\frac{v_{x r}^{2}}{E_{x}}, \quad \beta_{22}=\frac{1}{E_{\theta}}-\frac{v_{x \theta}^{2}}{E_{x}} \text {, } \\
& \beta_{12}=-\frac{v_{\theta r}}{E_{\theta}}-\frac{v_{x \theta} v_{x r}}{E_{x}}, \quad \beta_{66}=\frac{1}{G_{r \theta}}, c=\frac{a}{b}, \quad g_{1}=\frac{2}{\beta}\left(1-c^{\beta}\right)+\left(1+c^{\beta}\right) \ln c \text {, } \\
& g=\frac{\left(1-c^{2}\right)}{2}-\frac{k\left(1-c^{k+1}\right)^{2}}{(k+1)\left(1-c^{2 k}\right)}+\frac{k c^{2}\left(1-c^{k-1}\right)^{2}}{(k-1)\left(1-c^{2 k}\right)}
\end{aligned}
$$

Obviously, the through-thickness failure starts at the location where the radial stress, $\sigma_{r}(r, \theta)$, has the maximum value. The next potential failure location can be predicted in the delaminated sublaminates by the similar way. Taking an example of Panel A-I, the radial stress distribution of the intact R-section (Fig. 8) indicates that the through-thickness failure will initiate at the 5th ply which has the maximum value of the 
radial stress. After that, for the delaminated sublaminates I and II respectively, the initiation of through-thickness failure will occur at the 2nd and 8th plies. Therefore, in addition to the interfaces at the maximum delamination induced by edge impact, surface-based cohesive contact is also inserted at above-mentioned interfaces with the highest risk of delamination, because of the high interlaminar stresses introduced by the R-sections. For Panels A-I and B-I, delamination is considered between plies 2-3, 5-6, and 8-9 only, while that is defined between plies 3-4, 6-7, 11-12 and 14-15 for Panel C-I. Additionally, a "general contact" algorithm has been applied between the plies, in order to avoid unrealistic penetration.

The boundary conditions, namely the "anti-buckling knife edges" and the "bottom clamping blocks", are simply simulated by constraining the corresponding degree of freedom of the nodes. A longitudinal compression displacement, relatively to the loading conditions, has been applied at the lower end of the stiffened panel in an opportune speed value. Although the loading rate in the CAEI test is controlled with $0.02 \mathrm{~mm} / \mathrm{s}$ to obtain the ideal quasi-static test condition, it is simulated by means of the dynamic FE code ABAQUS/Explicit to overcome severe convergence difficulties encountered with implicit analysis when modeling issues with high material and geometrical non-linearity. The loading rate is chosen at $3.75 \mathrm{~m} / \mathrm{min}$ to reduce CPU time.

\section{Results and discussions}

\subsection{Numerical and experimental comparison of failure load}

Applied load versus global strain curves, obtained by the FE models, exhibits that good correlation is achieved with average peak loads measured during the CAEI tests in 
the graph of Fig. 9. Compared to experimental results, the ultimate failure loads, corresponding to maximum load-carrying capacities of stiffened composite panels, are predicted to within 15\% of experimental results (-2.5\% for Panel A-I, 3.4\% for Panel B-I and 12.6\% for Panel C-I, respectively). The response of pristine panels has been included for comparison. Obviously, edge impact damage can lead to significant stiffness and strength reductions under compressive loading. Numerical results show that the damaged panels of configurations A-I, B-I and C-I fail at 38.5\%, 42.0\% and $40.7 \%$, respectively, of the load carried by the pristine panels. The susceptibility of the free edge of the I-stiffener to damage due to impact loading is demonstrated.

There is a distinct knee point in each load-strain curve of the stiffened composite panel (Fig. 9), regardless of specimen configurations. This knee point is discovered to be associated with the complete fracture of the upper flange and web of the impacted stiffener in the FE analysis. Before the knee point, the load-strain curve of edge impacted stiffened panel coincides perfectly with that of intact one, which indicates that edge impact damage may not have a remarkable influence over the structural stiffness and load-carrying capacity of the overall structure until the occurrence of the broken web. However, once encountering compressive destruction of the upper flange with edge impact damage and the corresponding web, the specimen's load-carrying capacity will decrease dramatically, in both experimental and numerical analyses. Even if the results will be different depending on the stiffness ratio of the stiffener to the skin, the complete fracture of the impacted upper flange and the web controls the failure mechanisms and the residual strength of the specimen. The predicted points of residual 
strength, corresponding to both complete fracture of the impacted upper flange and the web and ultimate failure of the stiffened composite panel, are in vicinity of the data bands formed by measured points, as shown in Figs. 10(a) and 10(b), which validates the failure formulation proposed. It is worth noting that the predicted ratios between the fracture strength and the ultimate failure strength $\left(F_{\text {web }} / F_{\text {panel }}\right)$ are generally a little lower than the ratios gained by experiments, as illustrated in Fig. 10(c). For Panels A-I, B-I and C-I, respectively, the average ratios are $0.99,0.98$ and 0.98 in the CAEI test, while those ratios are $0.91,0.90$ and 0.89 in the numerical simulation. Considering that the final collapse of the specimen is determined by the failure of the whole edge impacted stiffener, including the fracture of the bottom flange and debonding failure of the skin-to-stiffener interface, this phenomenon is probably attributed to numerically overestimating the failure load of the bottom flange belonging to the edge impacted stiffener. Additional out-of-plane bending moment, which is introduced by the fracture of the impacted web, will be imposed on the central position of the bottom flange and corresponding skin. Moreover, accompanied with the increment of the central out-of-plane deformation, this additional bending moment will generate significant interlaminar stresses that can cause premature through-thickness failure (i.e. delamination) and should not be ignored. However, such effect of interlaminar stresses is not taken into account in the present FE model, from the perspective of reducing computational amount. Though, of course, calculation errors become greater, especially for the specimen with thick flanges, such as Panel C-I, the results presented still demonstrate acceptably predictive capabilities of the proposed method without 
increasing the amount of elements and deteriorating the computational efficiency, due to the requirement of extra modeling about the through-thickness behaviour (i.e. the increment of cohesive elements).

In particular, in order to evaluate the effect of through-thickness failure (delamination), which may occur in the R-section of the undamaged curved laminate belonging to the impacted stiffener, on the specimen's load carrying capacity, a similar FE model of Panel A-I is established except inserting cohesive behaviour at any interface of the undamaged curved laminate (the C-shaped laminate). It can be seen that when compared with the values given by the model considering delamination, the web fracture load and the panel failure load obtained by the model without considering delamination in the R-section are nearly $11.1 \%$ higher and $7.2 \%$ higher (see in Fig. 11), respectively. The result indicates that due to additional bending moments caused by the asymmetry of bearing loads around the edge impacted region, even the delamination of R-sections belonging to the curved laminate without impact damage, to some extent still affects the ultimate failure load of the I-stiffened composite panel.

\subsection{Final failure modes of I-stiffened composite panel}

The final failure modes and locations of I-stiffened panels, during the CAEI tests, are shown in Fig. 12(a). It can be observed that the impacted I-shaped stiffener of each specimen configuration fractured through the edge impact location at the middle height of the panel, while no obvious failure of other two stiffeners is detected. Meanwhile, debonding failure at the skin-to-stiffener interfaces covers the whole panel. The numerically predicted fiber compressive damage map of Fig. 12(b) indicates that the 
fiber compressive fracture has developed severely inside the plies at the middle of the impacted stiffener when the specimen completely loses its bearing capacity, which means thoroughgoing fracture in practice. Besides, the phenomenon of complete debonding can be clearly found at the interfaces between skin and all three stiffeners in the FE simulation. Above all, the simulated results exhibit a good correlation with experimental observations. It indicates that the propagation of fiber compressive failure and interfacial delamination plays a significant role in the compressive mechanism piloting the residual strength after edge impact.

\subsection{CAEI damage scenario of I-stiffened composite panel}

\subsubsection{Strain distribution}

Due to the similarity of the damage scenario for all specimens, in this section only Panel B-I is presented as an illustrative example. First of all, the scenario of damage propagation of the impacted upper flange and web during the loading process is investigated in detail, because under compressive loading, internal damage grows from the edge impact location and the failure mechanisms of the stiffener with edge impact damage controls the load carrying capacity of the whole stiffened composite panel. The strain-load curves of strain gauges, namely G93, G94, G111 and G112, which are located back-to-back on the center of the impacted upper flange and web along the longitudinal direction (Fig. 3), are compared to the experimental results in Fig. 12. A relatively good quantitative match with the experimental observations is provided by numerical simulations. The predicted strain-load curves of strain gauges G93 and G94 give us an indication about the local buckling load of the impacted upper flange. 
Obviously, at a predicted compressive load of about $924 \mathrm{kN}$, strains of top and bottom strain gauges bonded on the other side of the edge impact location diverge, as shown in Fig. 13(a). This phenomenon is conventionally related to variations in top and bottom compressive strains caused by buckling undulations in the upper flange. Practically at the same time, affected by the post-buckling deformation of the delaminated semi-elliptical region induced by free edge impact, similar strain divergence of the back-to-back strain gauges G111 and G112 at the stiffener web is detected in Fig. 13(b). Even though in the CAEI tests, the local buckling load of some specimens can hardly be recorded due to no clear divergence in strains between pairs of back-to-back gauges near the impact location, for the specimen B-I-01, its strain-load curves of G93 and G94 begin to change in two opposite direction at the compressive load of about $1050 \mathrm{kN}$. This divergence phenomenon becomes apparent at the load of about $1194 \mathrm{kN}$. Consequently, the predicted local buckling load of Panel B-I is within $12 \%$ of average local buckling load recorded in the experiments (about $1050 \mathrm{kN}$ ). Afterwards, accompanied with the propagation of fiber compressive failure and delamination, high oscillation of predicted curves occurs, which can be attributed to the deterioration of stress computing at Gauss integral points and unstable interaction response between contacting surfaces as soon as internal failure initiates. When the load reaches around $1302 \mathrm{kN}$ (within 5.2\% of average measured load about $1373 \mathrm{kN}$ ), corresponding to the complete fracture of the upper flange and the web, sudden changes of the strain-load curves for strain gauges G93, G94, G111 and G112 are observed.

After the impacted upper flange and the web break off in the middle 
(corresponding to $1302 \mathrm{kN}$ in the numerical simulation), strain-load curves for the back-to-back strain gauges on the central skin (G9 and G10 in Fig. 14(a)) turn directly into nonlinearity form linearity and their slopes change into two opposite direction. Considering that no internal damage is detected in the skin, it is mainly attributed to out-of-plane bending deformation emerged at the central skin which is severely weakened the support from the impacted stiffener when complete fracture occurs. This buckling shape can influence the strain distribution in the exterior and interior areas of the central skin. Moreover, as expected, additional load will transfer from the damaged upper flange and web to the remaining structure, thanks to the load redistribution between the skin and stiffeners according to their stiffness ratio. It will result in an increase of compression strain of strain gauges located on the intact structure and 'jumping' down of corresponding strain-load curves, as shown in Figs. 14 (b)-(d). Whereafter, when the load reaches $1388 \mathrm{kN}$, fiber compressive failure of the bottom flange is discovered near the position where the strain gauge G47 is bonded. As a consequence, the compression strain of the central skin (G50 in Fig. 14(b)) rapidly increases. As the compressive load increases till the ultimate failure load of $1488 \mathrm{kN}$, the strain-load curves of the remaining intact structure exhibits strong instability (see red circles in Figs. 14(c) and (d)), due to failure initiation and propagation in the bottom flange of the edge impacted stiffener and the skin-to-stiffener interfaces. In summary, during the loading phase, the predicted strain-load curves of representative strain gauges show a reasonably good match with those measured in CAEI tests.

\subsubsection{CAEI failure process}


The propagation mechanisms of both fiber compressive failure and delamination, which dominate the specimen's ultimate load carrying capacity under compression loading, are studied. The fiber compressive fracture and delamination processes of the impacted stiffener are presented in Fig. 15 and Fig. 16, respectively. The cross section is placed at the middle of the stiffened panel. Note that when the scalar stiffness degradation for cohesive surfaces (CSDMG) reaches the value 1, it represents complete stiffness degradation and hence delamination. Meanwhile once the value of the state variable (SDV11) equals to 1, the fiber compressive failure initiates. Considering the similarity for all specimens, in this paper only specimen B-I is taken into consideration.

In the initial phase of compression, as illustrated in Fig. 15(a), when the load reaches approximately $779 \mathrm{kN}$, fiber compression fracture firstly occurs near the impact-induced indented zone, due to the stress concentration which is caused by a sudden change of the longitudinal stiffness and additional bending moment at the boundary of the indented zone. The interfacial delamination is simultaneously triggered by fiber failure (Fig. 16(a)). The onset location of both interlaminar and intralaminar failure is on the impact backside of the C-shaped laminate (curved sublaminate C). Then, from the edge impacted site, fiber compressive failure propagates quickly, compared with other directions, along the transverse width perpendicular to the applied load. At the load of $924 \mathrm{kN}$, the edge impacted side of the upper flange has completely broken off and lost its load-bearing capability, as shown in Fig. 15(b). Due to significant stiffness reduction of the impacted site, additional load will instantaneously transfer to the undamaged site of the upper flange and also the undamaged web. It is responsible 
for localized buckling deformation of the upper flange and web, as observed divergence in strain-load curves (see Fig.13), both numerically and experimentally. Besides, it can be seen that due to additional bending moments introduced by load-bearing asymmetry, delamination, prior to intralaminar failure, has already generated at the interfaces of upper R-sections (Fig. 16(b)). The result suggests that the through-thickness failure is reasonably required to be simulated. Subsequently, with increasing applied load to roughly $1257 \mathrm{kN}$, fiber failure and delamination, which initiate at the R-section and propagate to the upper flange and web, can be detected in the curved sublaminate B (Figs. 15(c) and 16(c)). The complete fracture of the upper flange and web for the impacted stiffener rapidly occurs when loaded to $1302 \mathrm{kN}$, as presented in Figs. 15(d) and 16(d), which has a remarkable influence over the structural stiffness and load-carrying capacity of the overall structure due to the appearance of a knee point in the structural load-strain curve. At the moment, the load instantaneously transfers from the broken upper flange and web to the intact structure including the bottom flange of the impacted stiffener, the skin and other two stiffeners. The residual structure in the FE analysis, obviously, is able to carry this additional load, otherwise the collapse of the stiffened panel will occur in a flash because the current load reaches or exceeds the extreme load-carrying capacity of the residual structure. Interfacial delamination in the bottom flange (sublaminate D) might be prematurely formed (see in Fig. 16(d)), compared to fiber breakage, as a consequence of significant interlaminar stresses that are generated by the out-of-plane bending moment. Finally, the impacted stiffener is crushed as soon as the compression load is increased to the ultimate failure load of 
approximately $1448 \mathrm{kN}$.

Hence, the primary reason about the destruction of the I-stiffened composite panel, subjected to edge impact, is the physical controlling mechanism that including the local buckling, damage initiation and propagation from the edge impact region, the fracture of the curved sublaminates subjected to the combined effect of compression and bending loads, and the ultimate collapse of the stiffener induced by edge impact damage.

\section{Conclusions}

In this paper, a phenomenological-based mechanical finite element model has been proposed and successfully used to capture the ultimate strength, failure modes and strain variation of the I-stiffened composite panels, of which the free edge of the stiffener upper flange is subjected to low-velocity impact. The main conclusions of the CAEI numerical investigation are presented:

A simplified method based on the experimental edge impact damage morphology has been proposed to incorporate complex edge impact damage into the CAEI numerical model, which regards the presence of the maximum delamination, the permanent indentation and intralaminar damage as a key consideration. The intralaminar damage region induced by impact is considered as concentric semi-elliptical inclusions, except for the fiber fracture region in outer plies. With the help of a composite damage model comprising both progressive CDM model and surface-based cohesive contact model, the proposed method has exhibited a high degree of capability in capturing both the qualitative and quantitative aspects, such as global failure load, damage parameter maps, applied load-strain curves and strain distribution 
for the CAEI analysis of I-stiffened composite panels with a range of configurations.

In general, irrespective of specimen configurations, the CAEI failure process of the I-stiffened composite panel can be distinctly divided into two phases that are easy to be identified by a keen point in the load-strain curve: the complete fracture of the impacted upper flange and corresponding web, and the ultimate collapse of the remaining structure. Due to large loss of structural stiffness, the residual strength is seriously affected by compressive destruction of the impacted upper flange and web.

The fiber compressive failure and interfacial delamination are key factors to determine the failure mechanism of stiffened composite panel under compressive loading. Typically, the physical controlling failure mechanism of the impacted stiffener includes the local buckling, damage initiation and propagation from the edge impact region, the fracture of the curved sublaminates subjected to the combined effect of compression and bending loads, and the ultimate collapse of the stiffener induced by edge impact damage.

In particular, it seems that the interlaminar stresses play a significant role in compressive failure of the bottom flange and R-sections, as a result of additional bending moment generated by the structural out of-plane deformation or load-bearing asymmetry. The residual strength may be partly overestimated for the I-stiffened panel if neglecting the influence of through-thickness failure (i.e. delamination) in the FE analysis, especially for panels with relatively thick thickness. Therefore, instead of inserting cohesive behaviour at each interface, an analytical method is adopted to reduce the number of interfaces through determining the potential failure location under the 
critical force, and it gives acceptable prediction. To conclude, new approaches, which should be theoretically reasonable and computationally affordable, might be necessary in the future to take into account more accurately the promoting influence of interlaminar stresses on the material failure during the CAEI process, particularly for the R-sections and bottom flange of the edge impacted stiffener.

\section{Acknowledgments}

This work was supported by the National Science Foundation of China (No. 11572152), and Shanghai Aircraft Design and Research Institute.

\section{References}

1. Ghelli D, Minak G. Low velocity impact and compression after impact tests on thin carbon/epoxy laminates. Composites: Part B 2011; 42: 2067-2079.

2. Riccio A, De Luca A, Di Felice G, et al. Modelling the simulation of impact induced damage onset and evolution in composites. Composites: Part B 2014; 66: 340-347.

3. Breen C, Guild F, Pavier M. Impact damage to thick carbon fibre reinforced plastic composite laminates. J Mater Sci 2006; 41: 6718-6724.

4. Malhotra A, Guild F, Pavier M. Edge impact to composite laminates: experiments and simulations. J Mater Sci 2008; 43: 6661-6667.

5. Andrew T R, Richard B. Compressive static strength model for impact damaged laminates. Composites Science and Technology 2009; 69: 2301-2307.

6. Koo J M, Choi J H, Seok C S. Prediction of residual strength of CFRP after impact. Composites: Part B 2013, 54: 28-33.

7. Riccio A, Scaramuzzino F, Perugini P. Embedded delamination growth in 
composite panels under compressive load. Composites: Part B 2001, 32: 209-218.

8. Sepe R, De Luca A, Lamanna G, et al. Numerical and experimental investigation of residual strength of a LVI damaged CFRP omega stiffened panel with a cut-out. Composites: Part B 2016; 102: 38-56.

9. Tan W, Falzon BG, Chiu LN, et al. Predicting low velocity impact damage and Compression-After-Impact (CAI) behaviour of composite laminates. Composites: Part A 2015; 71: 212-236.

10. Chen PH, Shen Z, Wang J Y. Strength prediction of notched composite laminate. Composite Science and Technology 2001; 61(9): 1311-1321.

11. Chen PH, Shen Z, Wang J Y. A new method for compression after impact strength prediction of composite laminates. Journal of Composite Materials 2002; 36(5): 589-610.

12. Rivallant S, Bouvet C, Abiabdallah E, et al. Experimental analysis of CFRP laminates subjected to compression after impact: the role of impact-induced cracks in failure. Compsoite Structures 2014; 111: 147-157.

13. Xiong Y, Poon C. A prediction method for the compressive strength of impact damaged composite laminates. Composite Structures 1995; 30: 357-67.

14. Gonzalez E, Maimi P, Camanho P, et al. Simulation of drop weight impact and compression after impact tests on composite laminates. Composite Structures 2012; 94(11): 3364-78.

15. Rivallant S, Bouvet C, Hongkarnjanakul N. Failure analysis of CFRP laminates subjected to compression after impact: FE simulation using discrete interface 
elements. Composites: Part A 2013; 55: 83-93.

16. Rhead AT, Marchant D, Butler R. Compressive strength of composite laminates following free edge impact. Composites: Part A 2010; 41: 1056-1065.

17. Malhotra A, Guild F J. Impact damage to composite laminates: effect of impact location. Appl Compos Mater 2014; 21: 165-177.

18. Ostre B, Bouvet C, Minot C, et al. Experimental analysis of CFRP laminates subjected to compression after edge impact. Composite Structures 2016; 152: 767-778.

19. Li N, Chen PH. Experimental investigation on edge impact damage and Compression-After-Impact (CAI) behavior of stiffened composite panels. Composite Structures 2016; 138: 134-150.

20. Vyas GM, Pinho ST, Robinson P. Constitutive modelling of fibre-reinforced composites with unidirectional plies using a plasticity-based approach. Composite Science and Technology 2011; 71: 1068-74.

21. Abi Abdallah E, Bouvet C, Rivallant S,et al. Experimental analysis of damage creation and permanent indentation on highly oriented plates. Composite Science and Technology 2009; 69: 1238-45.

22. Deuschle HM. 3D failure analysis of UD fibre reinforced composites: Puck's theory within FEA. Germany: University Stuttgart, 2010.

23. ABAQUS. ABAQUS 6.14 Documentation. Dessault systems; 2014.

24. Ye Q, Chen PH. Prediction of the cohesive strength for numerically simulating composite delamination via CZM-based FEM, Composites: Part B 2011; 42: 


\section{6-1083.}

25. Xiao SS, Chen PH, Ye Q.Prediction of damage area in laminated composite plates subjected to low velocity impact, Composite Science and Technology 2014; 98: $51-56$.

26. Turon A, Davila CG, Camanho PP, Costa J. An engineering solution for mesh size effects in the simulation of delamination using cohesive zone models. Eng Fract Mech 2007; 74(10): 1665-82.

27. Caputo F, De Luca A, Sepe R. Numerical study of the structural behaviour of impacted composite laminates subjected to compression load. Composites Part B, 2015; 79: 456-465.

28. Mitrevski T, Marshall IH, Thomson R. The influence of impactor shape on the damage to composite laminates. Composite Structures, 2006; 76: 116-22.

29. Choi HY, Downs RJ, Chang FK. A new approach toward understanding damage mechanisms and mechanics of laminated composites due to low-velocity impact, part I. J Compos Mater 1991; 25(8): 992-1011.

30. Craven R, Pindoria S, Olsson R. Finite element study of compressively loaded fibres fractured during impact. Compos Sci Technol 2009; 69(5): 586-93.

31. P.P. Camanho, F.L. Matthews, A progressive damage model for mechanically fastened joints in composite laminates, J. Compos. Mater 1999; 33:2248-2280.

32. Hwang SF, Liu GH. Buckling behaviour of composite laminates with multiple delaminations under uniaxial compression. Composite Structures 2001; 53: 23-43.

33. ESDU. Through-the-thickness stresses and failure in the corner radius of a 
laminated composite section. The Royal Aeronatical Society; 1994.

34. Sun CT, Li S. Three-dimensional effective elastic contants for thick laminates. J Compos Mater 1988; 22: 629-639.

35. Puck A, Kopp J, Knops M. Guidelines for the determination of the parameters in Puck’s action plane strength criterion. Composites Science and Technology, 2002, 62: $371-378$.

36. Hinton M J, Kaddour A S, Soden P D. A comparison of the predictive capabilities of current failure theories for composite laminates, judged against experimental evidence. Composites Science and Technology. 2002, 62(12-13): 1725-1797.

37. Soden P D, Hinton M J, Kaddour A S. Biaxial test results for strength and deformation of a range of E-glass and carbon fibre reinforced composite laminates: failure exercise benchmark data. Composites Science and Technology. 2002, 62(12-13): 1489-1514.

38. Hinton M J, Kaddour A S, Soden P D. A further assessment of the predictive capabilities of current failure theories for composite laminates: comparison with experimental evidence. Composites Science and Technology. 2004, 64(3-4): 549-588.

39. Bazant ZP, Oh BH. Crack band theory for fracture of concrete. Mater Struct 1983; $16: 155-77$.

40. Lapczyk I, Hurtado J. A Progressive damage modeling in fiber-reinforced materials. Composites Part A, 2007, 38: 2333-2341.

41. Carpinteri A, Cornetti P, Barpi F, et al. Cohesive crack model description of ductile 
to brittle size-scale transition: dimensional analysis vs. renormalization group theory. Engineering Fracture Mechanics, 70, 1809-1939, 2003. 

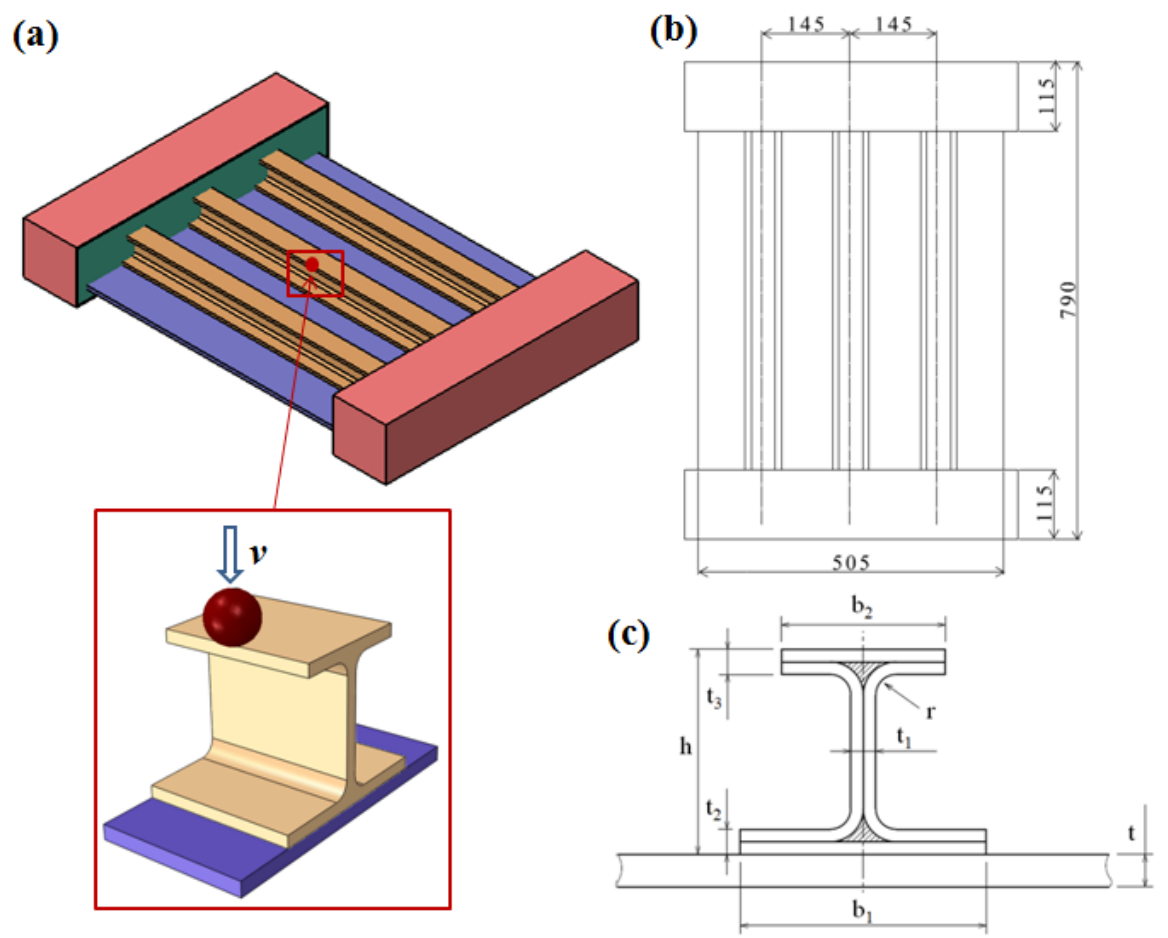

Fig. 1. (a) Principle of impact on the free edge of the I-shaped stiffener flange, (b) stiffened composite panel nominal dimensions (scale in mm) and (c) cross section of the stiffener and skin.

(a)

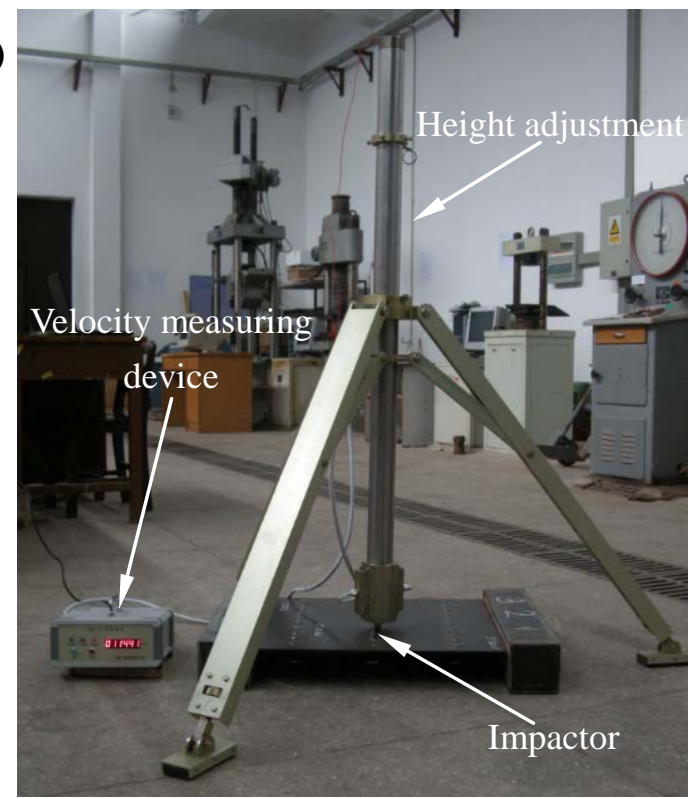

(b)

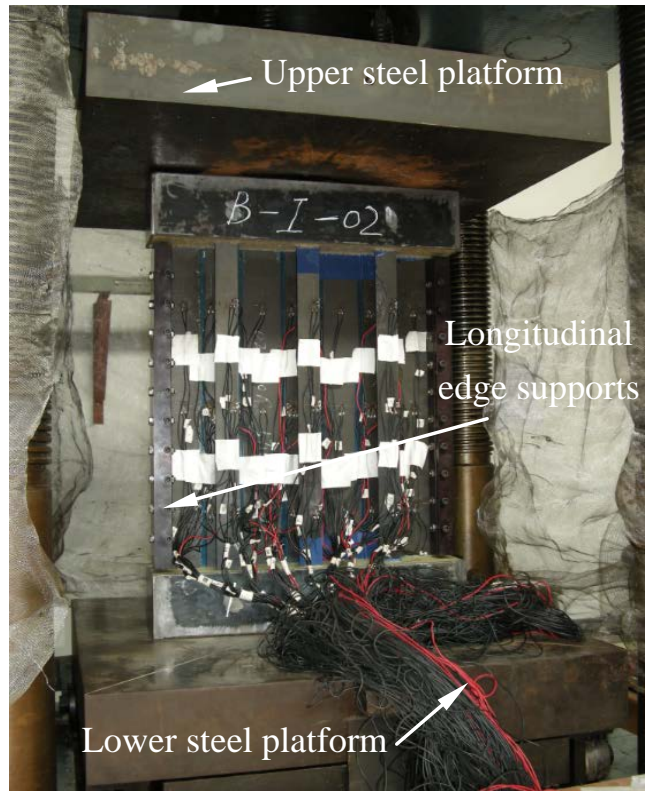

Fig. 2. Test instruments for (a) drop-weight impact test and (b) uniaxial compression test. 


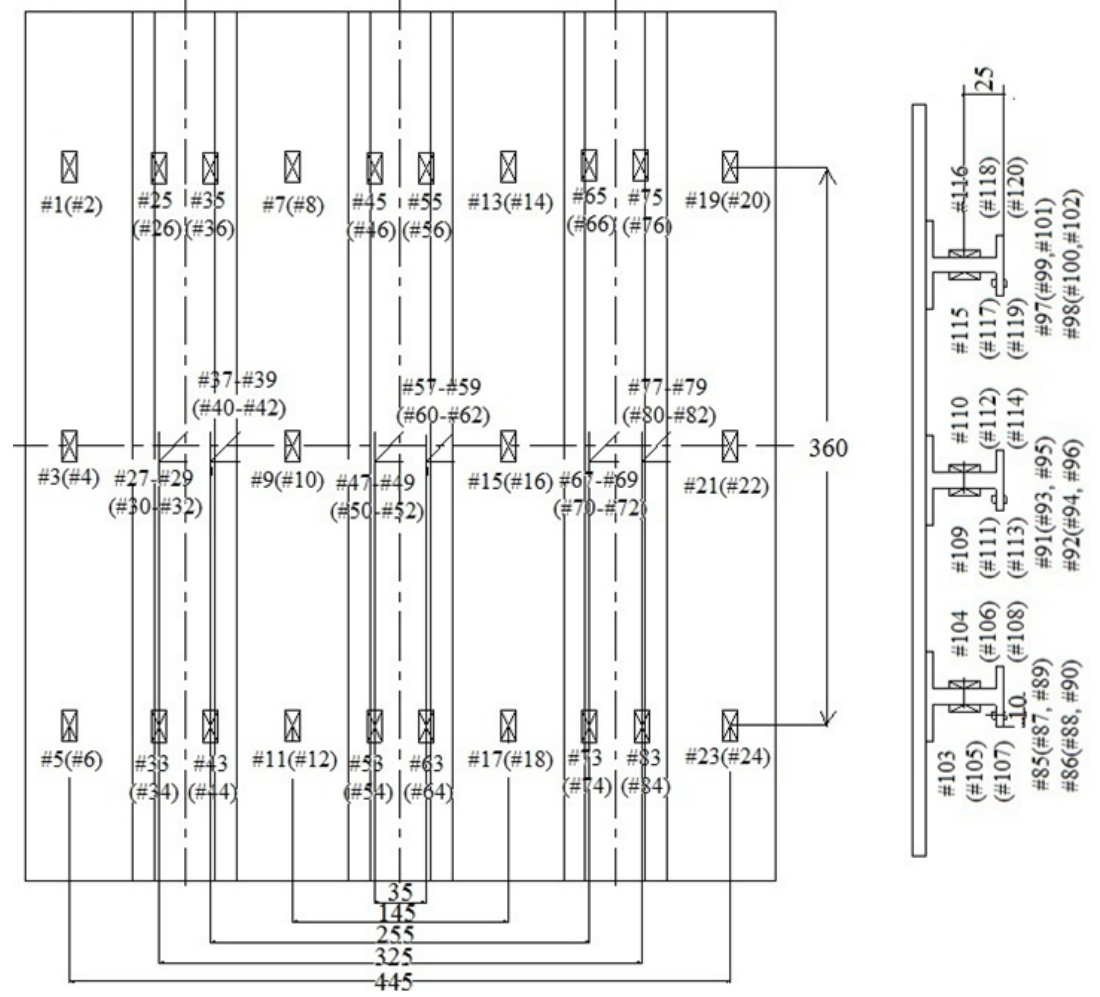

Fig. 3. Locations of the strain gauges.

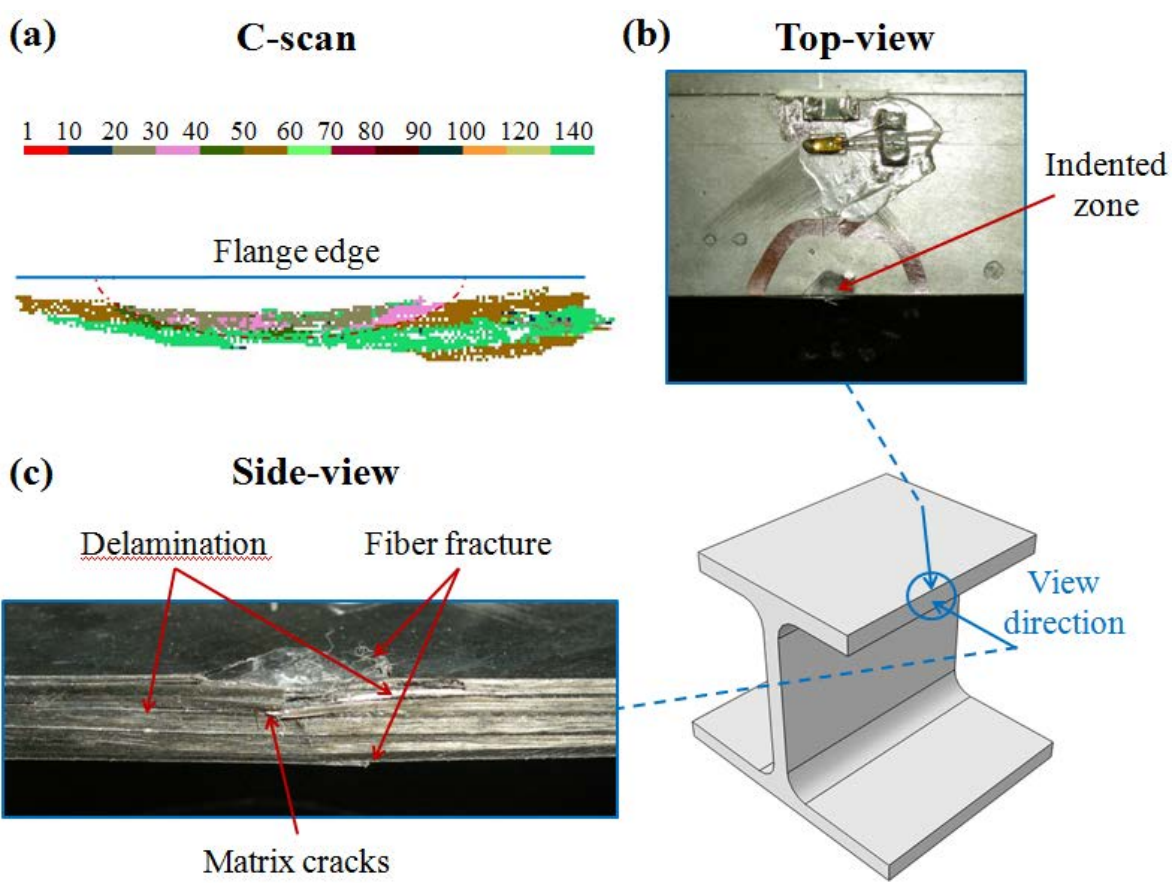

Fig. 4 Post-impact morphology of the I-stiffener edge: (a) C-scan image, (b) top-view visual inspection and (c) side-view visual inspection. 
(a)

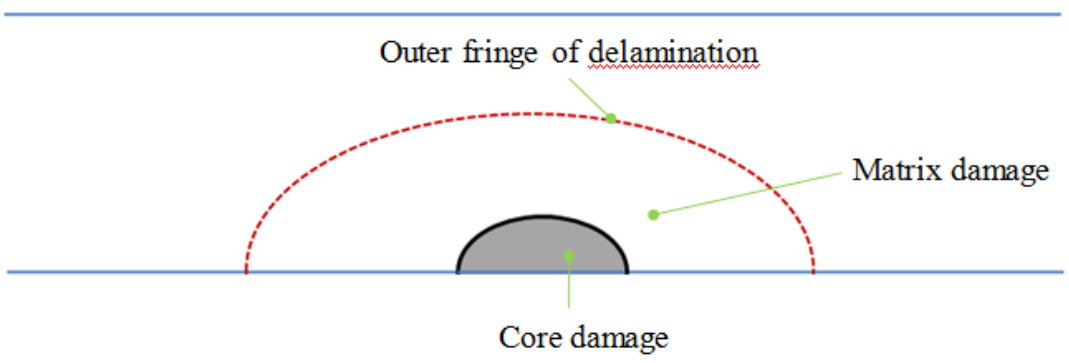

(Fiber and matrix damage)

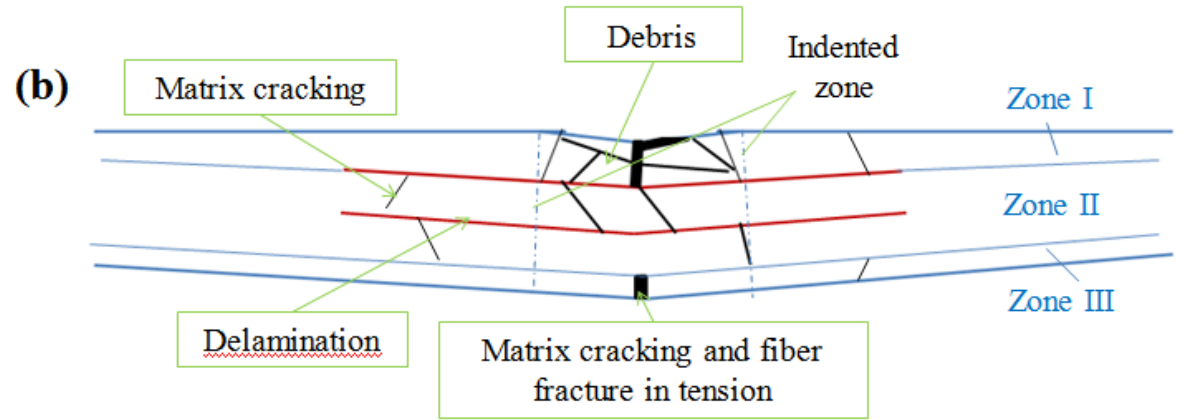

Fig. 5. Schematic of typical damage morphology induced by edge impact: (a) vertical view and (b) side view.

(a)

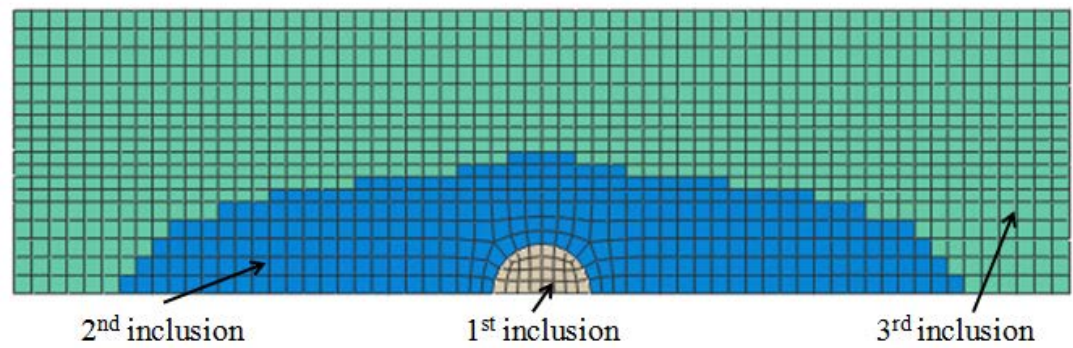

(b)

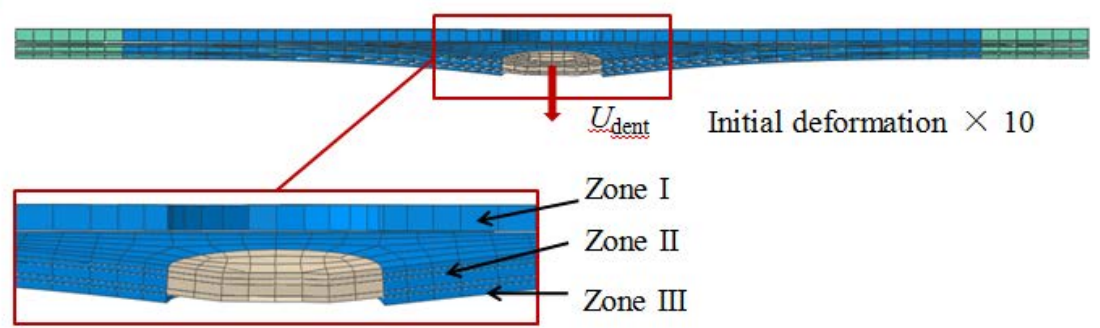

Fig. 6. (a) Subdivision in damage inclusions according to internal damage and (b) initial out-of-plane deformation due to the indented effect. 

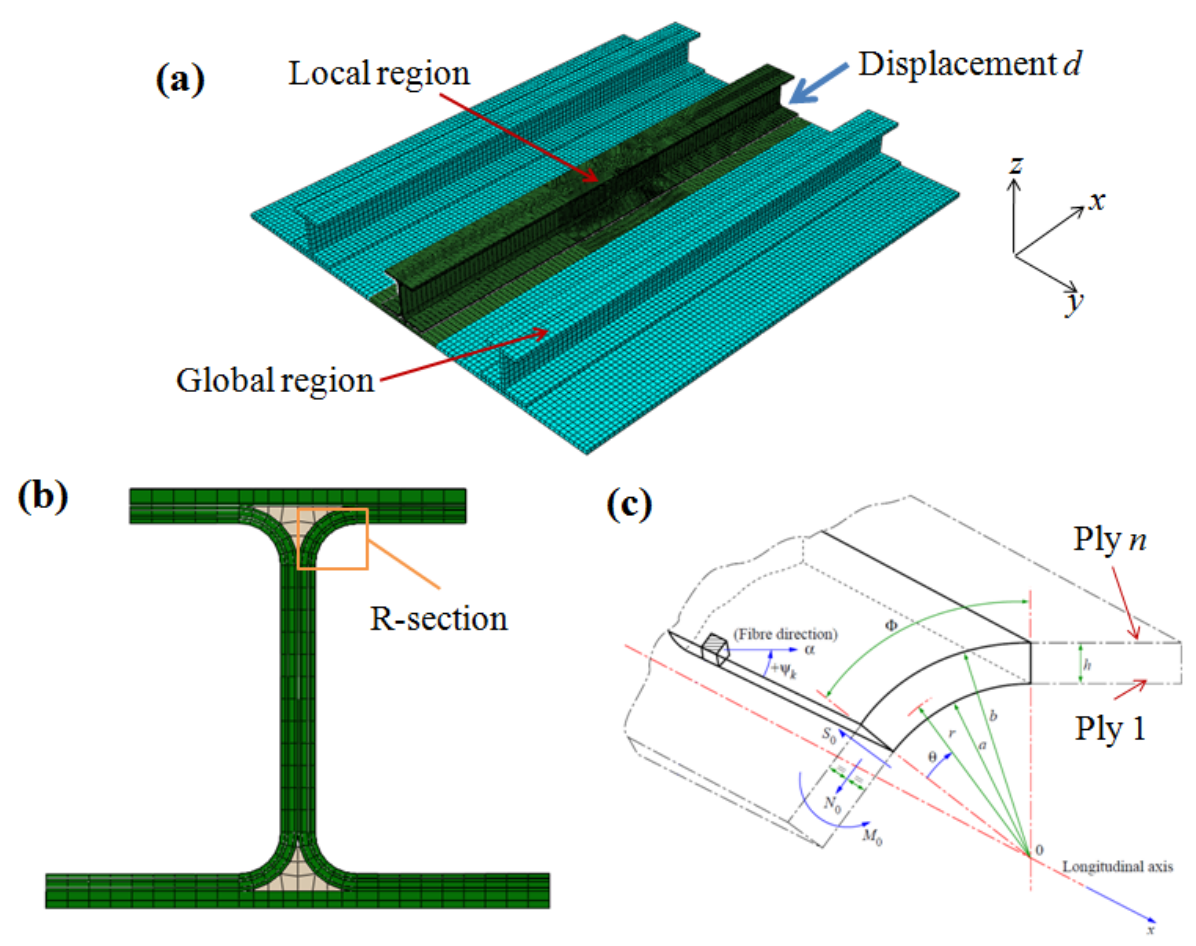

Fig. 7. (a) Numerical CAEI model of a stiffened composite panel, (b) details in the I-shaped stiffener and (c) geometric parameters and loading definition of the R-section.

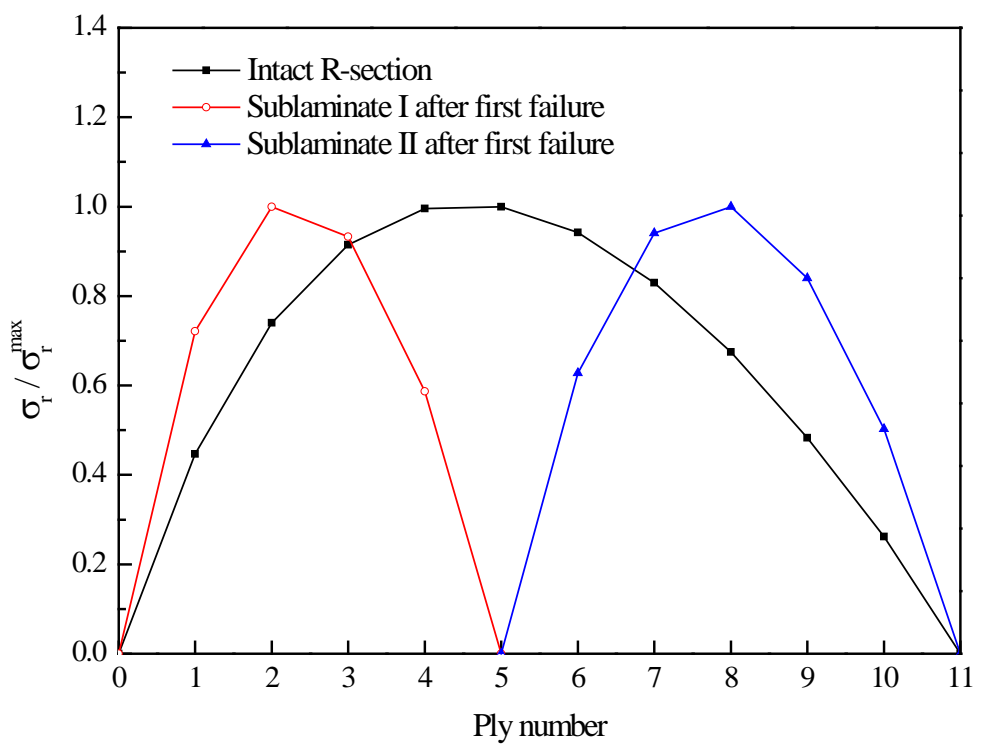

Fig. 8. Radial stress distribution curve along the radius direction. 

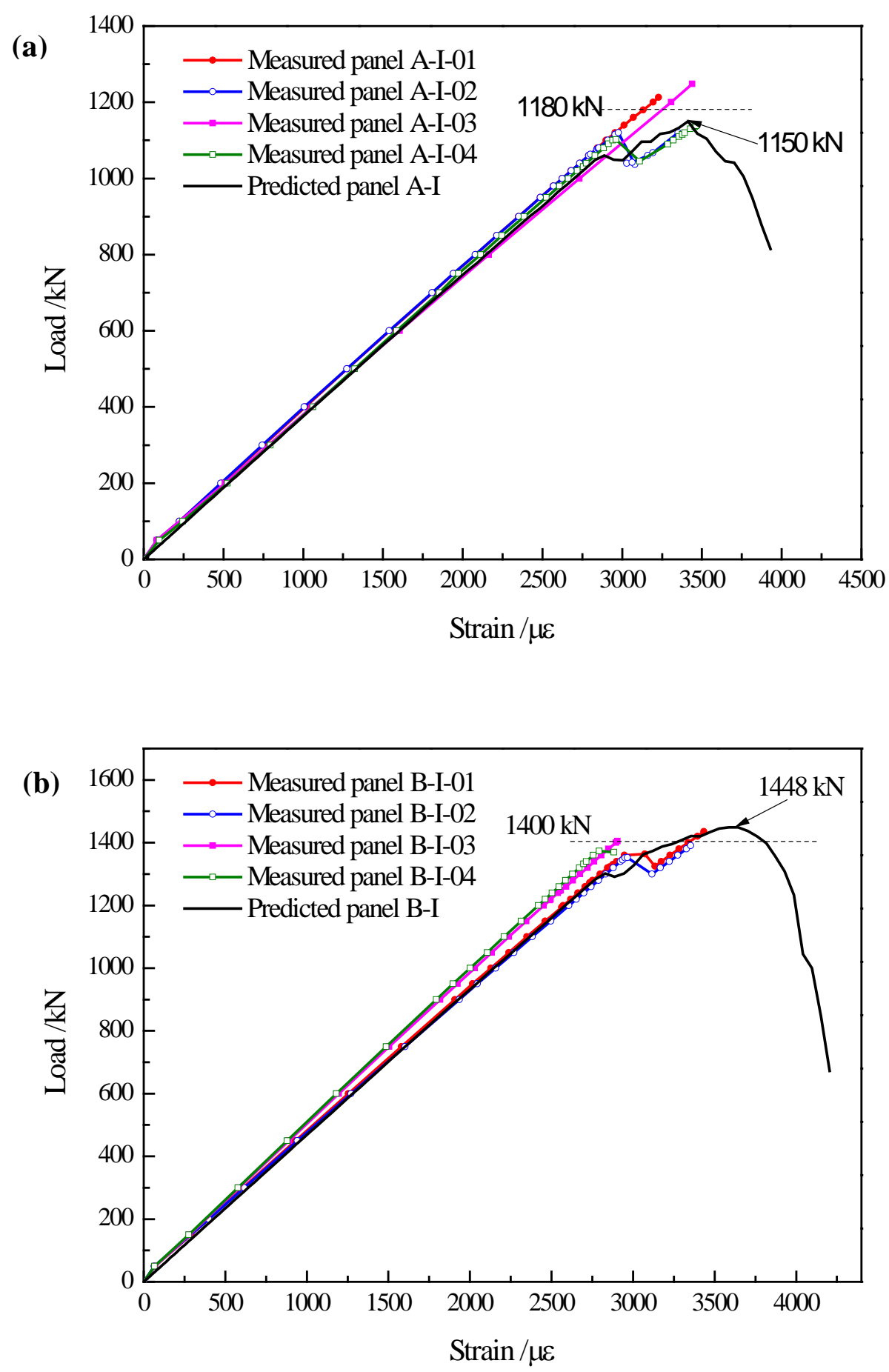

Fig. 9. Comparison between measured and predicted load-global strain curves for (a) Panels A-T, (b) B-T and (c) C-T 


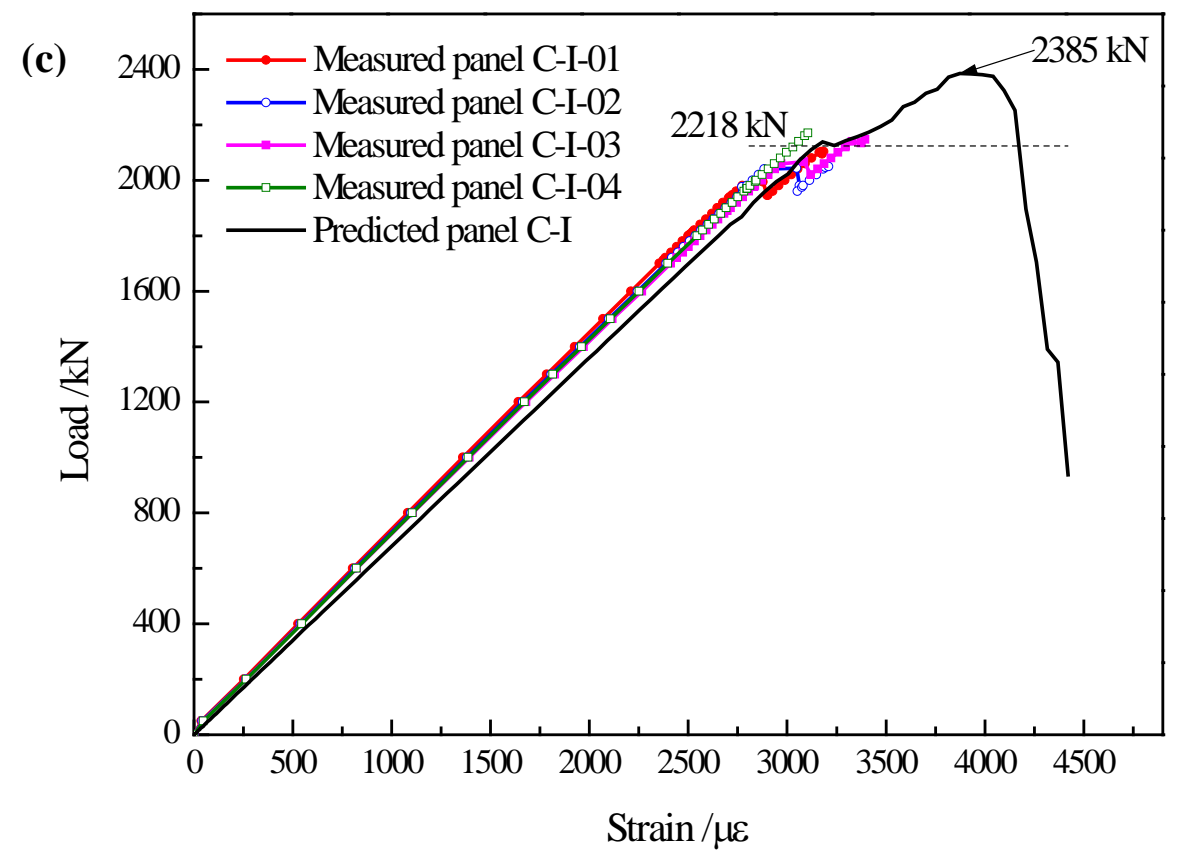

Fig. 9 (continued) 

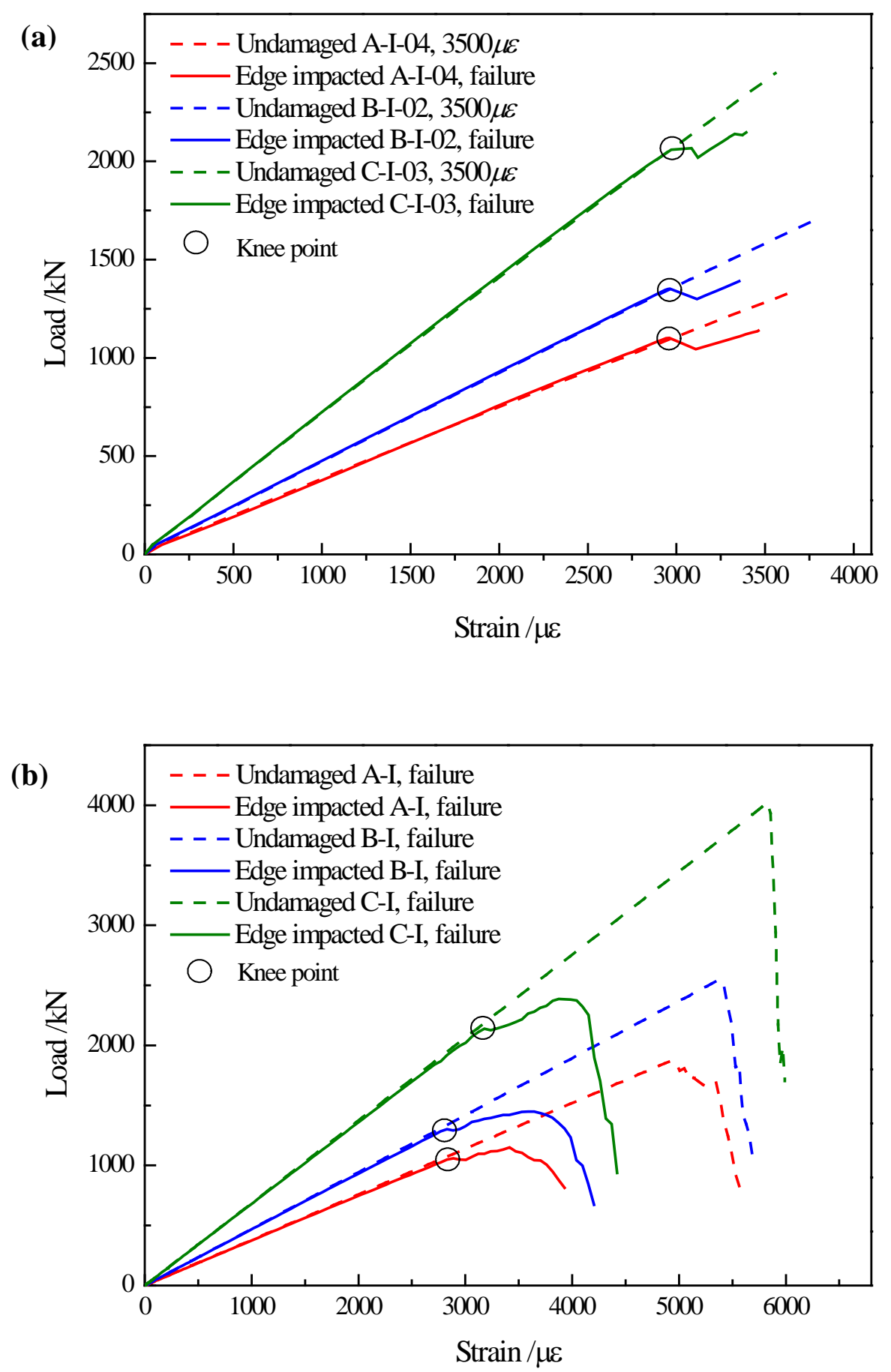

Fig. 10. Comparison in load-strain curves of undamaged and impacted panels during: (a)

CAEI experiments and (b) numerical simulations. 

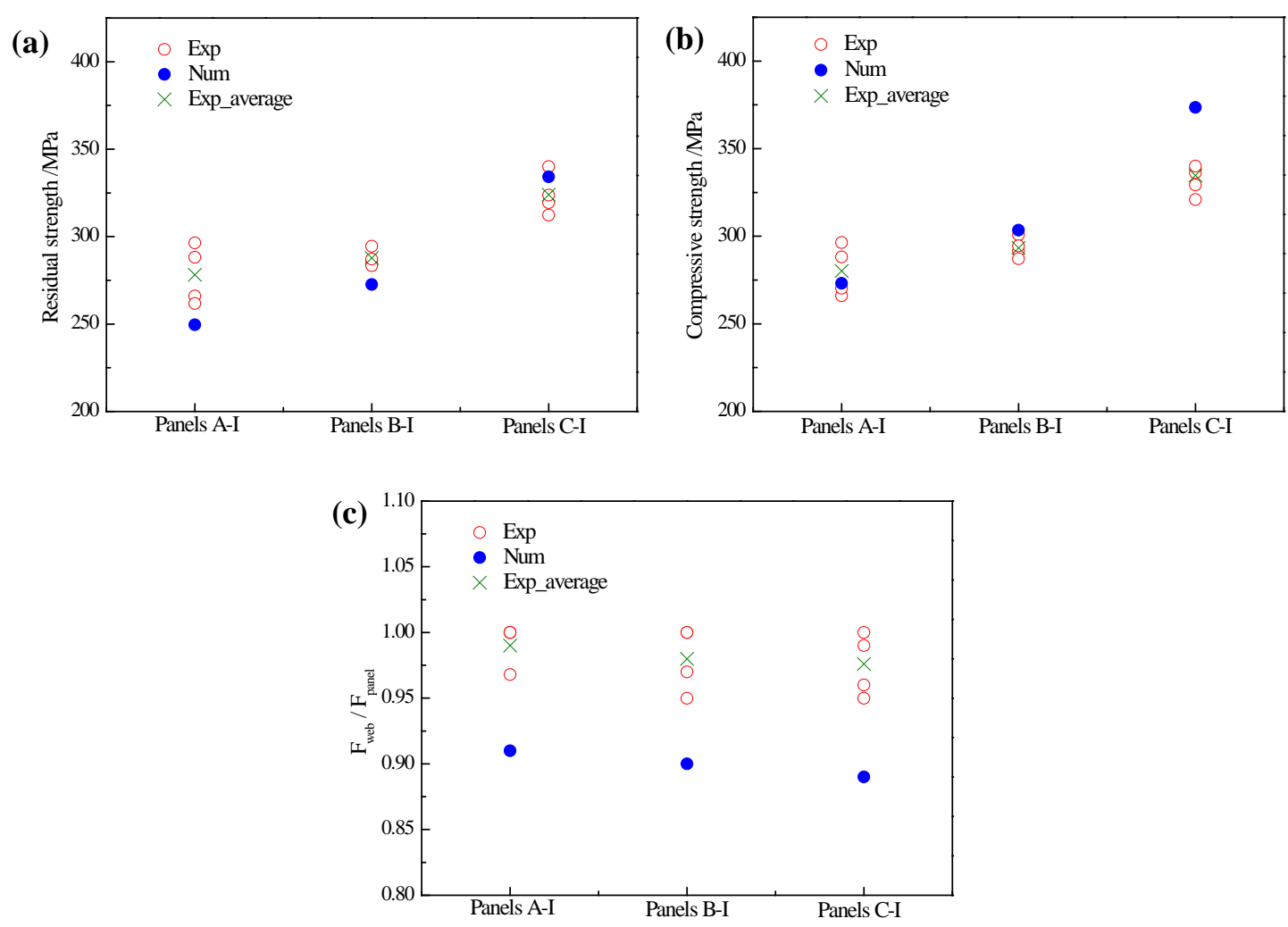

Fig. 11. Comparison between experimental and numerical compressive strength: (a) corresponding to the complete fracture of impacted upper flanges and webs, (b) corresponding to the ultimate failure of stiffened composite panels and (c) ratios. 


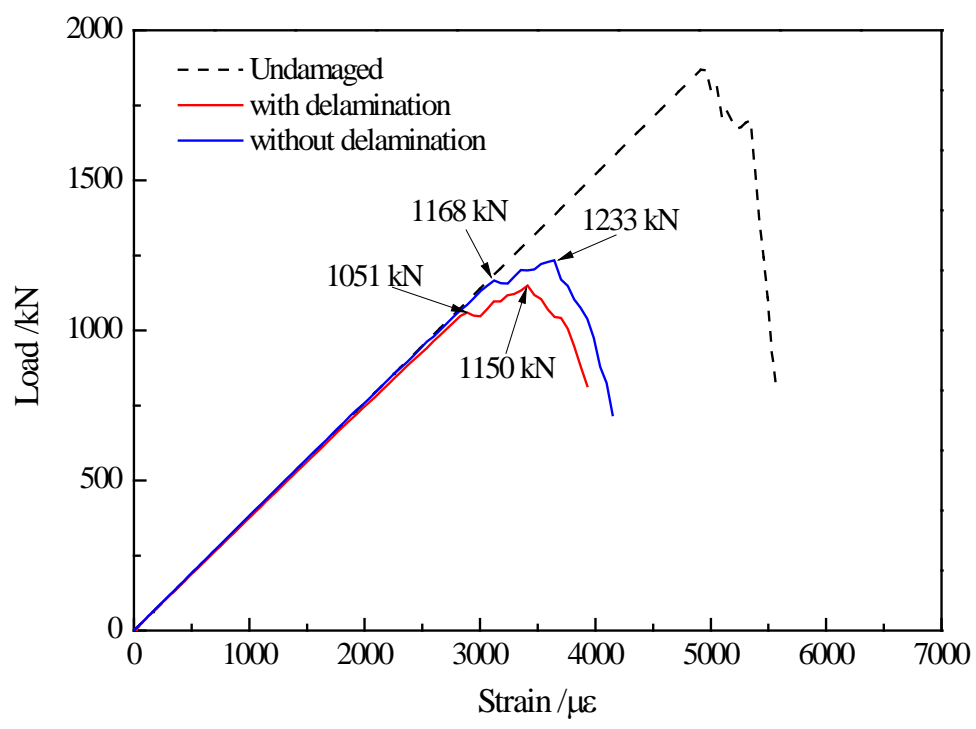

Fig. 12. Load-strain curves predicted by different FE models of stiffened composite panels. 
(a)

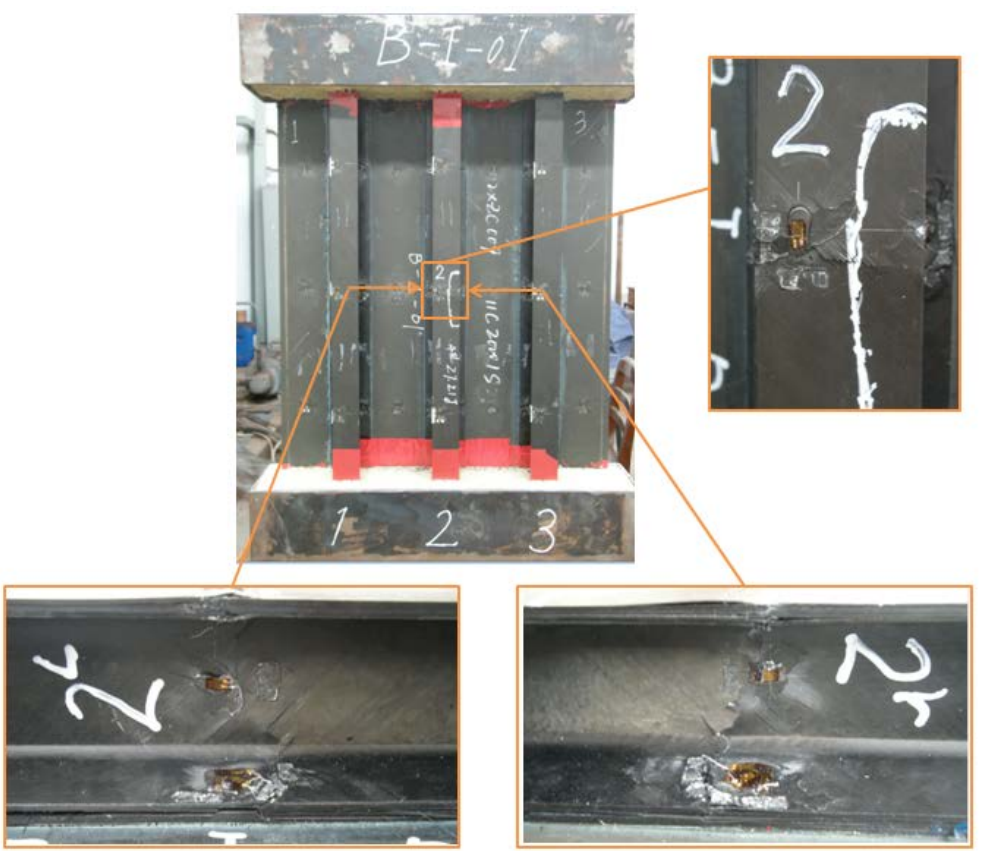

(b)

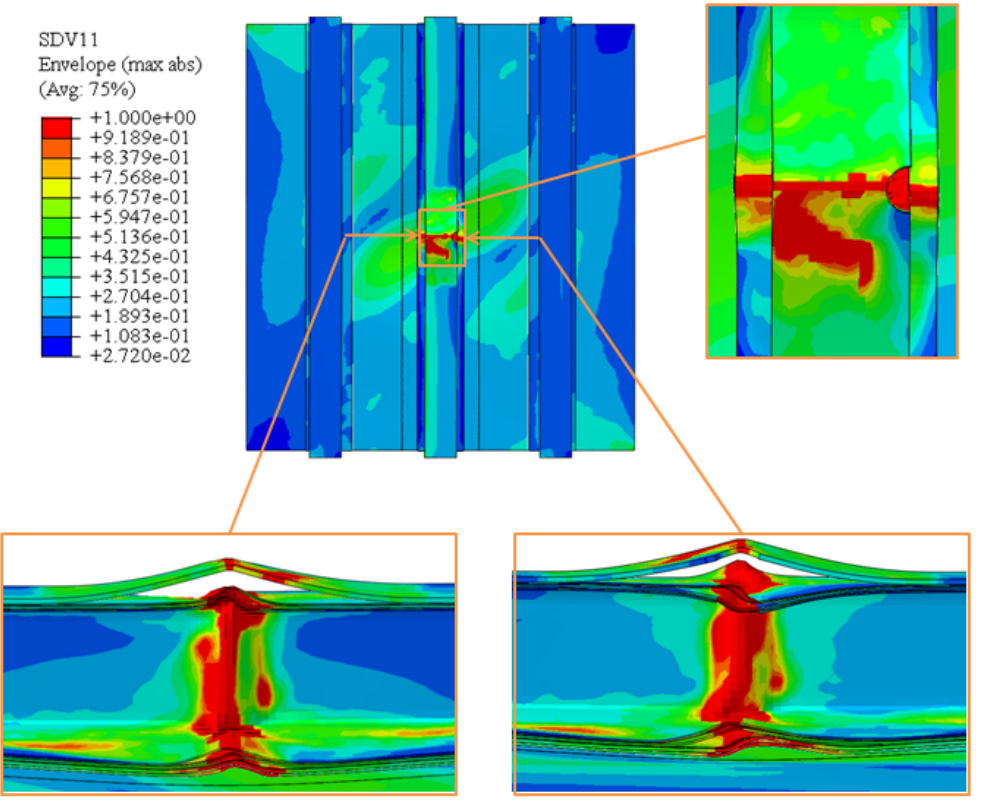

Fig. 13. Final failure maps of the stiffened composite panel: (a) representative failure modes in the CAEI test, (b) fiber compressive failure predicted by numerical simulation. 

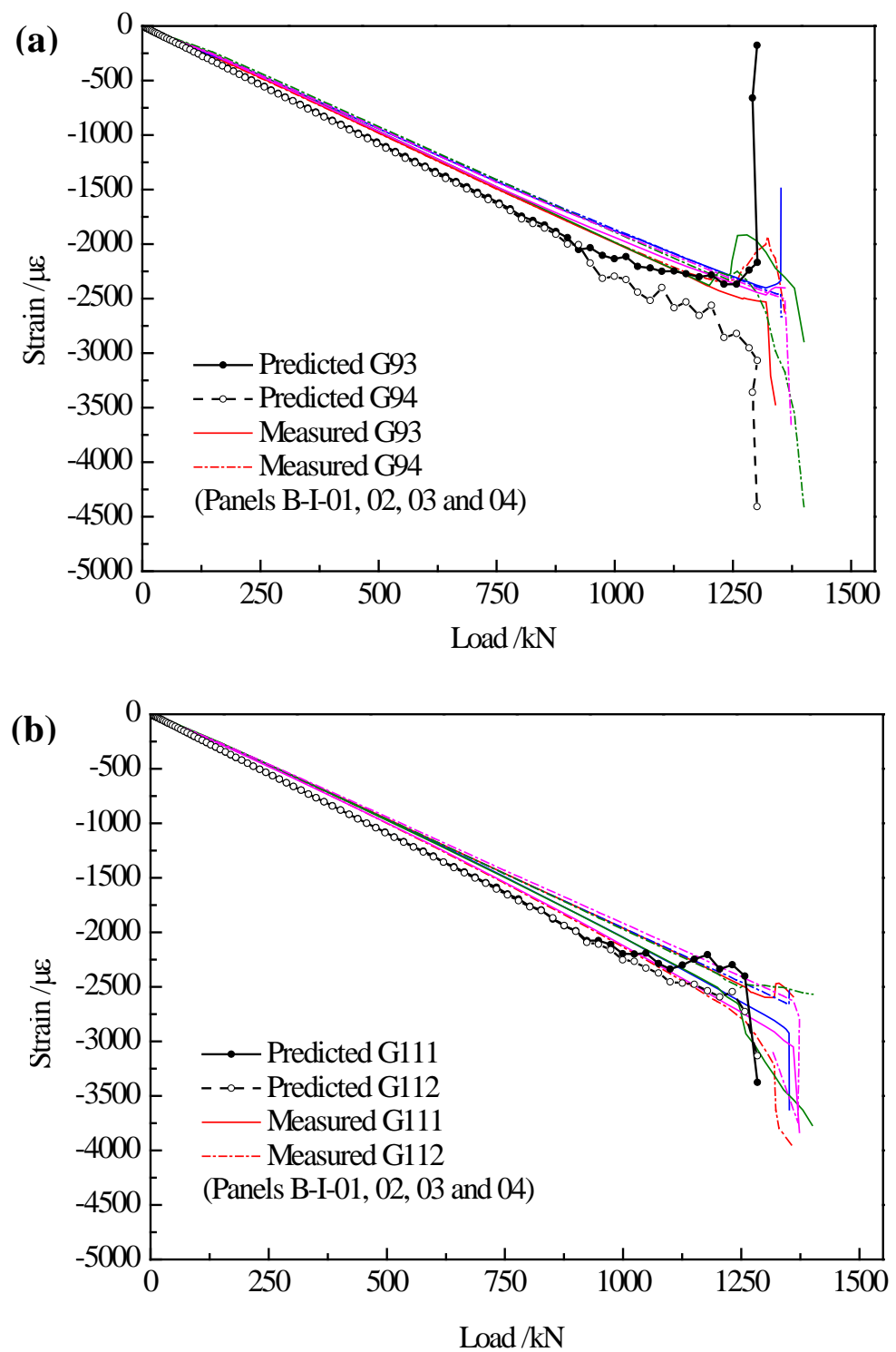

Fig. 14. Applied compressive load as a function of strains in: (a) the impacted upper flange and (b) the web based on numerical simulations and experiments. 

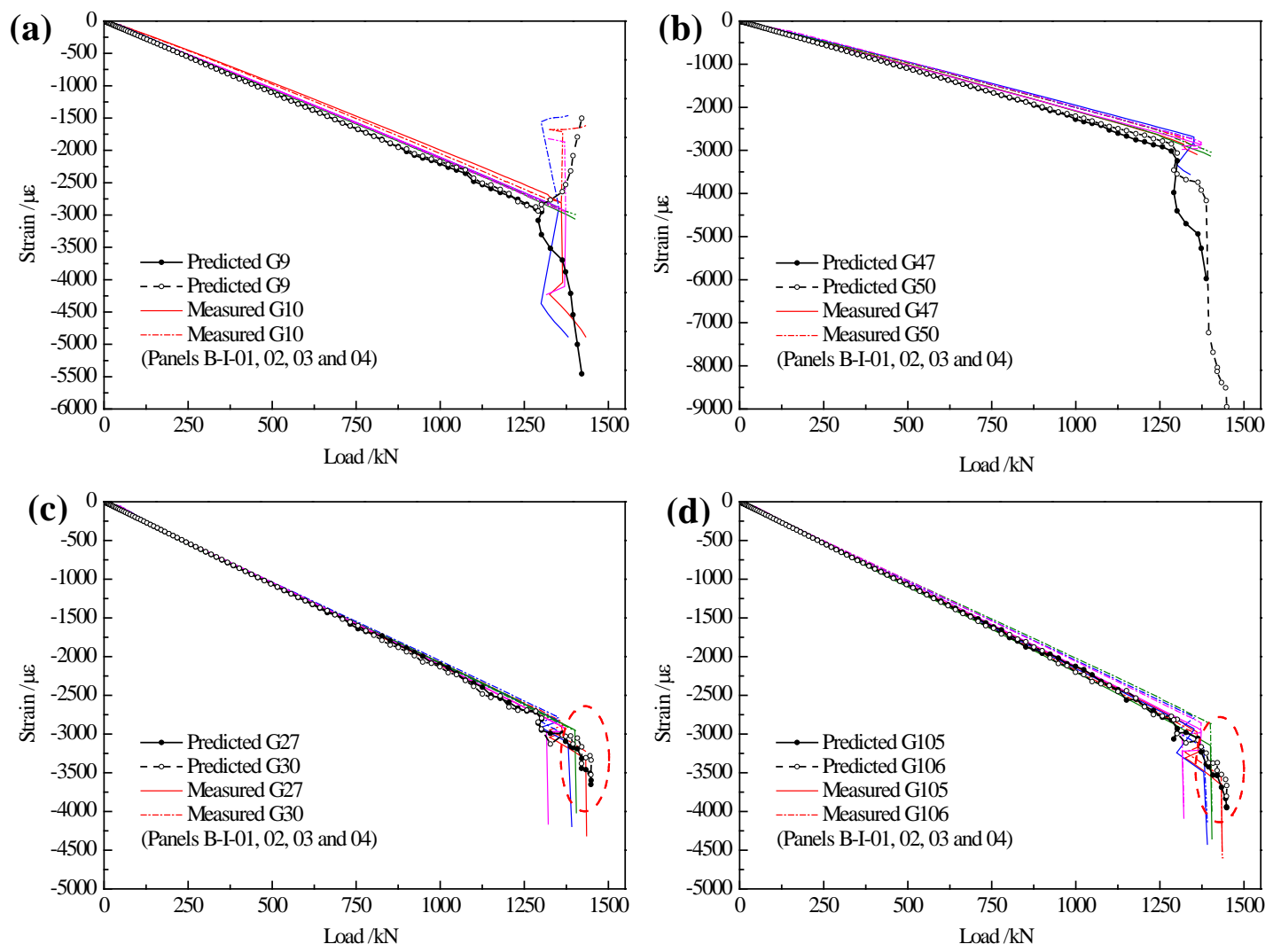

Fig. 15. Applied compressive load as a function of strains in: (a) the central skin, (b) the bottom flange of the impacted stiffener, (c) the bottom flange of the intact stiffener and (d) the web of the intact stiffener based on numerical simulations and experiments. 

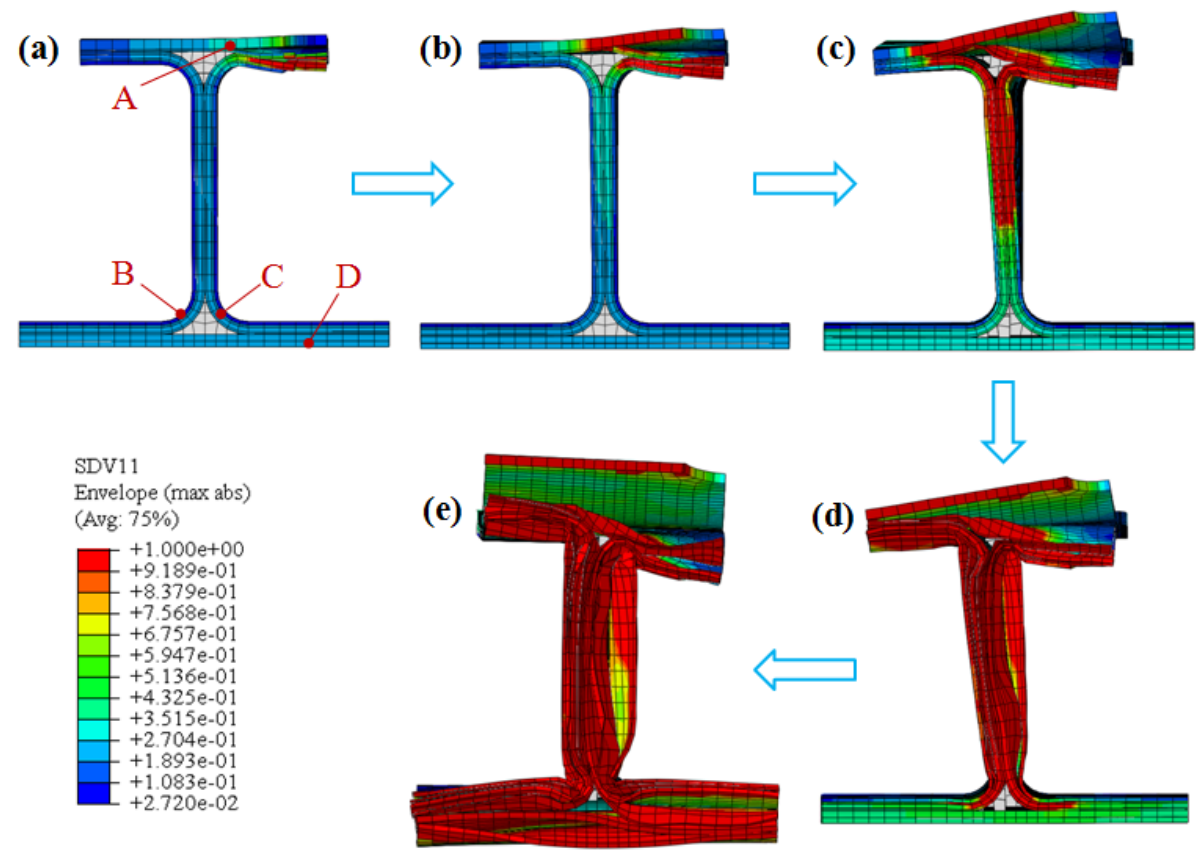

Fig. 16. Fiber compressive failure process of the edge impacted stiffener: applied load is equal to the value of (a) $779 \mathrm{kN}$, (b) $924 \mathrm{kN}$, (c) $1257 \mathrm{kN}$, (d) $1302 \mathrm{kN}$ and (e) $1448 \mathrm{kN}$.

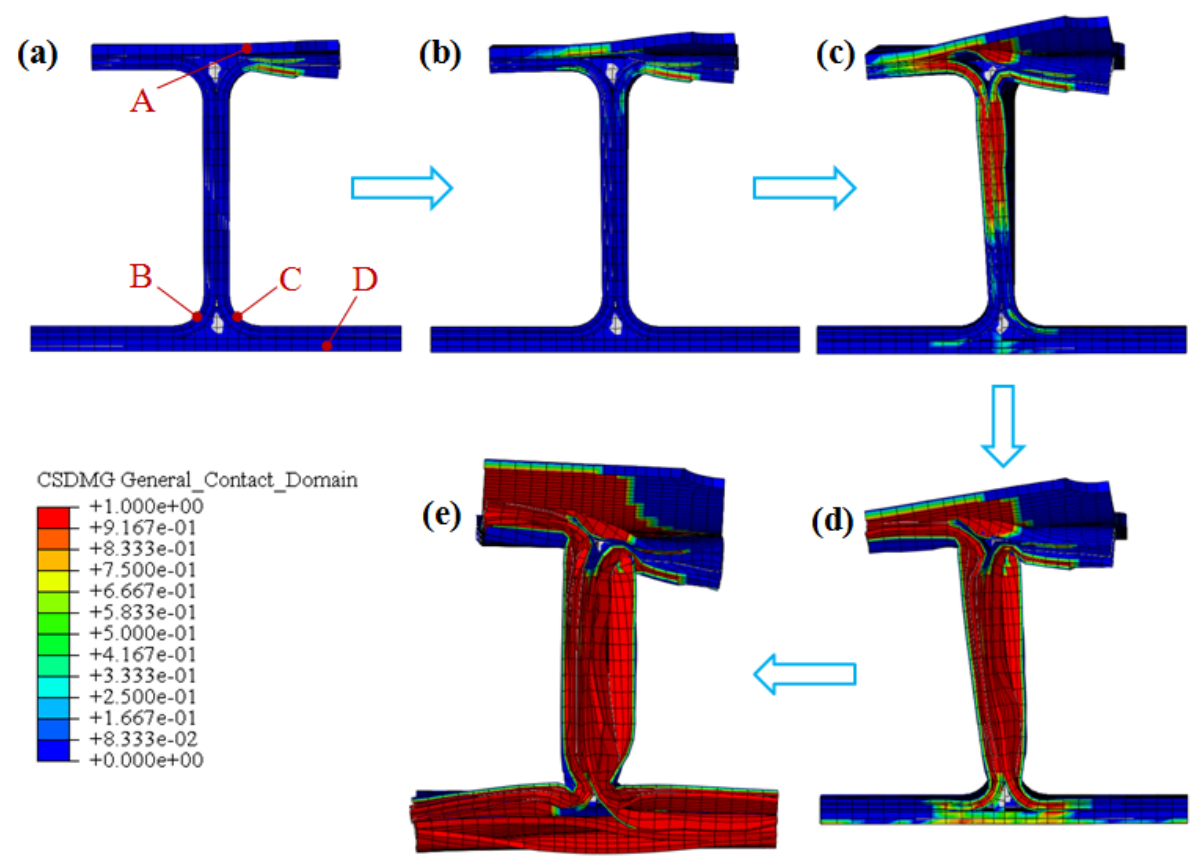

Fig. 17. Delamination process of the edge impacted stiffener: applied load is equal to the value of (a) $779 \mathrm{kN}$, (b) $924 \mathrm{kN}$, (c) $1257 \mathrm{kN}$, (d) $1302 \mathrm{kN}$ and (e) $1448 \mathrm{kN}$. 


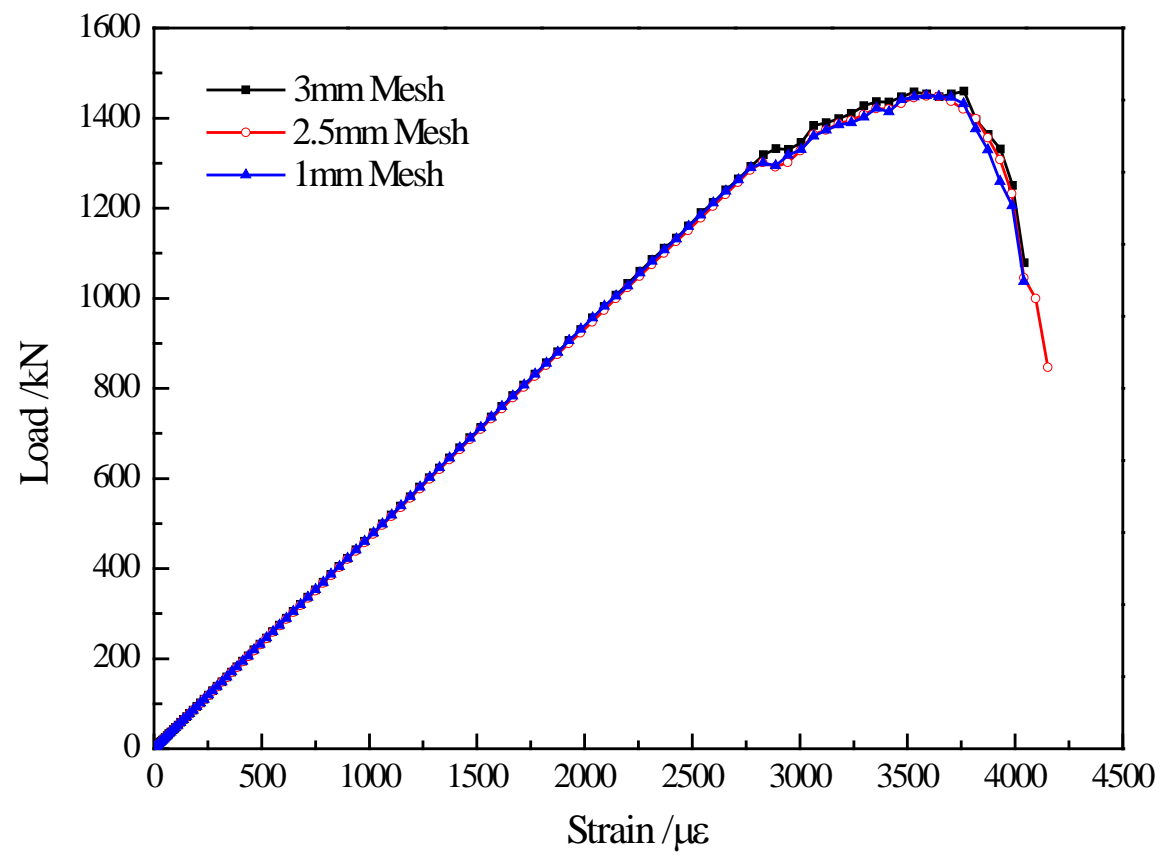

Fig. 18. Predicted load-global strain curves for different mesh densities.
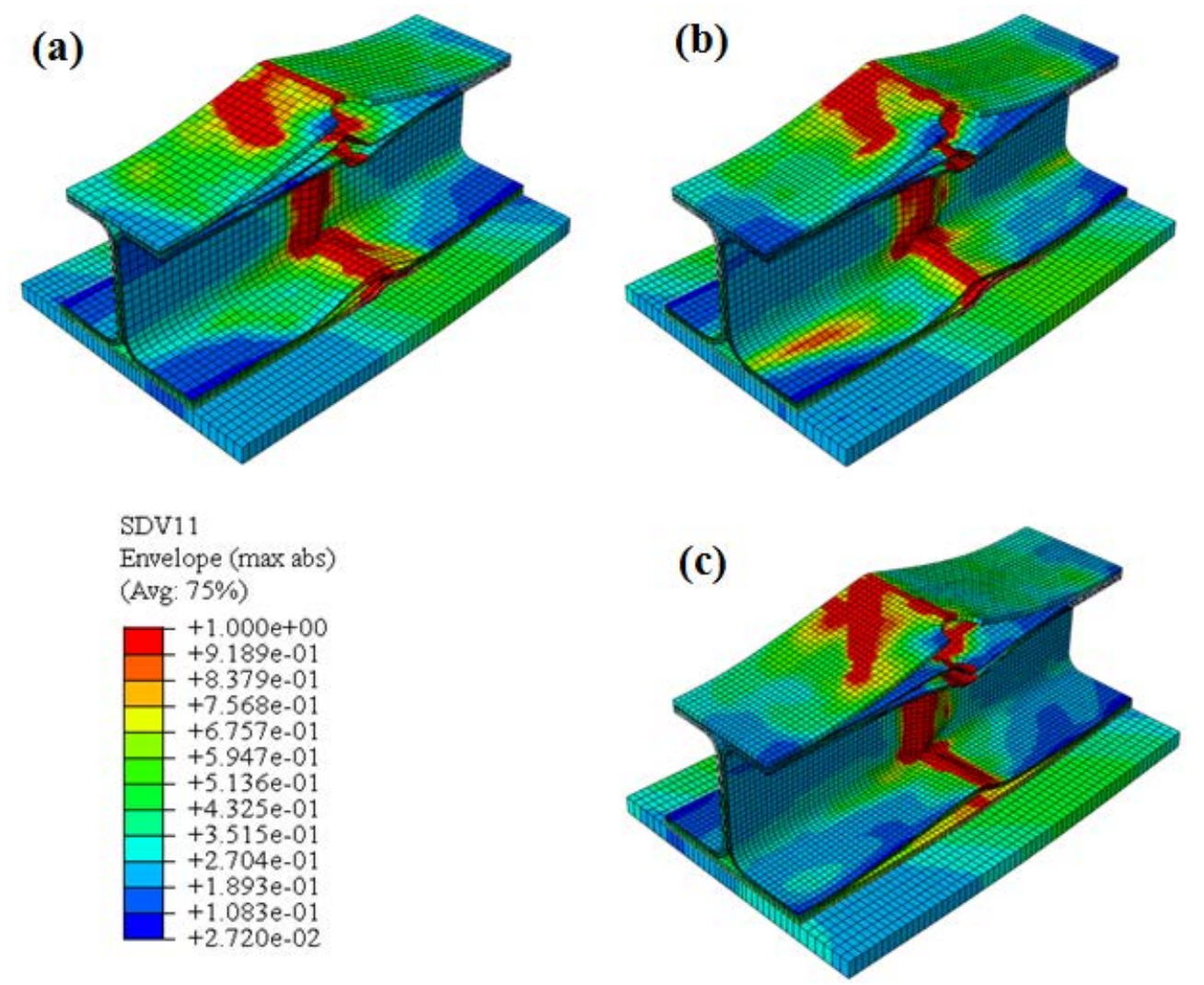

Fig. 19. Numerically final failure maps of fiber compressive failure for: (a) $3 \mathrm{~mm} \times 3$ $\mathrm{mm}$, (b) $2.5 \mathrm{~mm} \times 2.5 \mathrm{~mm}$ and (c) $2 \mathrm{~mm} \times 2 \mathrm{~mm}$. 
Table 1 Recommended inclination parameters [22, 35]

\begin{tabular}{llll}
\hline & $p_{\perp \square}^{\mathrm{t}}$ & $p_{\perp \square}^{\mathrm{c}}$ & $p_{\perp \perp}^{\mathrm{t}}, p_{\perp \perp}^{\mathrm{c}}$ \\
\hline GFRP & 0.30 & 0.25 & 0.20 to 0.25 \\
CFRP & 0.35 & 0.30 & 0.25 to 0.30 \\
\hline
\end{tabular}

Table 2 Unidirectional lamina material proprieties

\begin{tabular}{lll}
\hline IMS/X850 UD properties & \\
\hline$E_{1}$ & Longitudinal Young modulus & $165 \mathrm{GPa}$ \\
$E_{2}$ & Transverse Young modulus & $8.58 \mathrm{GPa}$ \\
$G_{12}$ & In-plane shear modulus & $4.57 \mathrm{GPa}$ \\
$v_{12}$ & Poisson's ratio & 0.331 \\
$R_{\square}^{\mathrm{t}}$ & Longitudinal tensile strength & $3071 \mathrm{MPa}$ \\
$R_{\square}^{\mathrm{c}}$ & Longitudinal compressive strength & $1747 \mathrm{MPa}$ \\
$R_{\perp}^{\mathrm{t}}$ & Transverse tensile strength & $88 \mathrm{MPa}$ \\
$R_{\perp}^{\mathrm{c}}$ & Transverse compressive strength & $271 \mathrm{MPa}$ \\
$R_{\perp}$ & In-plane shear strength & $143 \mathrm{MPa}$ \\
$R_{\perp \perp}$ & Interlaminar shear strength & $103 \mathrm{MPa}$ \\
$E_{\mathrm{f} 1}$ & Young modulus for fibers & $225 \mathrm{GPa}$ \\
$v_{\mathrm{f} 12}$ & Poisson's ratio for fibers & 0.2 \\
$G_{\mathrm{Ic}}$ & Critical ERR-Mode I & $0.314 \mathrm{~J} \mathrm{~m}{ }^{-2}$ \\
$G_{\mathrm{IIc}}$ & Critical ERR-Mode II & $1.081 \mathrm{~J} \mathrm{~m}{ }^{-2}$ \\
$t_{\mathrm{p}}$ & Ply thickness & $0.185 \mathrm{~mm}$ \\
$K_{\mathrm{N}}$ & Cohesive interface stiffness in the normal direction & $120000 \mathrm{GPa} / \mathrm{m}$ \\
$K_{\mathrm{S}}, K_{\mathrm{T}}$ & Cohesive interface stiffness in the shear direction & $43000 \mathrm{GPa} / \mathrm{m}$ \\
\hline
\end{tabular}

